\title{
Phospholipids in Cosmetic Carriers
}

\author{
Peter van Hoogevest and Alfred Fahr
}

\begin{abstract}
Phospholipids are attractive components in cosmetic products because of their natural origin and multifunctional properties. They are used, technically as surface-active compounds, but also as cosmetic actives and modulator of skin penetration. Three classes of phospholipids are being used in cosmetics: saturated and unsaturated phospholipids and monoacylphospholipids (lyso-phospholipids). Whereas the use of monoacylphospholipids is limited to technical use as emulsifiers, the cosmetic use of saturated and unsaturated phospholipids is much broader. The latter are used as actives; additionally saturated phospholipids are used as surface-active compounds, whereas unsaturated phospholipids are suitable to enhance skin penetration. The relation of phospholipids to nanotechnology is apparent when they are, e.g., used as an emulsifier in "nano-emulsions" and as component of "nano-liposomes", having particle sizes in the nano-range. Regulatory authorities discriminate, however, between nanoparticles comprising solid inorganic non-biodegradable particles, with potential (systemic) toxicity, and flexible lipid biodegradable carriers, respectively, comprising, e.g., phospholipids which are non-toxic [1] and fall apart in the skin. Since basically the particle characteristics in the formulation and the component of the particles are believed to cause the desired beneficial cosmetic skin effects, in this chapter the
\end{abstract}

P. van Hoogevest $(\square)$

Phospholipid Research Center, Im Neuenheimer Feld 515, 69120 Heidelberg, Germany

e-mail: pvanhoogevest@phospholipid-institute.com

A. Fahr

Professor Emeritus, Pharmaceutical Technology,

Friedrich-Schiller-University Jena, Jena, Germany

(C) The Author(s) 2019

J. Cornier et al. (eds.), Nanocosmetics, https://doi.org/10.1007/978-3-030-16573-4_6 
use and degree of skin interaction of especially natural phospholipids as cosmetics ingredient in traditional and nano-cosmetic carriers are described and demonstrated by means of illustrative products.

\section{Keywords}

Phospholipids - Liposomes - Emulsions - Lamellar structures - Solubilizers • Biocompatibility

\section{Abbreviations}

ATR-FTIR Attenuated total reflection-Fourier-transform infrared spectroscopy

CLE Corneocyte lipid envelope

COSMOS Cosmetics to optimize safety

DHA Docosahexaenoic acid (DHA, 22:6n-3)

Dil 1, 1'-dioctadecyl-3,3,3',3'-tetramethylindocarbocyanine perchlorate

DMEM Dulbecco's modified Eagle's medium

DNA Deoxyribonucleic acid

DPPC 1,2-dipalmitoylphosphaitdylcholine

DSPC 1,2-distearoylphosphatidylcholine

EPA Eicosapentaenoic acid (20:5n-3)

GMO Genetically modified organism

GPC Glycerophosphocholine

HA Hyaluronic acid

HET-CAM Hen's egg test on chorioallantoic membrane

HLB Hydrophilic-lipophilic balance

HPC Hydroxypropylcelullose

HSPC Hydrogenated soybean phosphatidylcholine

IFN Interferon

IP Identity preserved (i.e. non-GMO)

LUV Large unilamellar vesicle

MCT Medium-chain triglyceride

MLV Multilamellar vesicle

MMP Matrix metalloprotease

$\mathrm{NaFl} \quad$ Sodium fluorescein

NHDF Normal human dermal fibroblasts

NHEK Normal human epidermal keratinocytes

PA Phosphatidic acid

PC Phosphatidylcholine

PE Phosphatidylethanolamine

PG Phosphatidylglycerol

PI Phosphatidylinositol

PLA Phospholipase A

PLD Phospholipase D 


$\begin{array}{ll}\text { PMA } & \text { Phorbol myristate acetate } \\ \text { PS } & \text { Phosphatidylserine } \\ \text { RH } & \text { Relative humidity } \\ \text { RNA } & \text { Ribonucleic acid } \\ \text { SDS } & \text { Sodium dodecylsulphate } \\ \text { SLS } & \text { Sodium lauryl sulphate } \\ \text { sPLA2 } & \text { Secretory phospholipase A2 } \\ \text { SD } & \text { Standard deviation } \\ \text { SLM } & \text { Skin lipid matrix } \\ \text { SUV } & \text { Small unilamellar vesicle } \\ \text { TEWL } & \text { Transepidermal water loss } \\ \text { TGF } & \text { Transforming growth factor } \\ \text { TNF } & \text { Tumor necrosis factor } \\ \text { US-FDA } & \text { US Food and Drug Administration } \\ \text { UV } & \text { Ultraviolet }\end{array}$

\subsection{Introduction}

Since a few decades, material scientists developed new materials which could be prepared in particle form at the nanoscale. By introducing these materials in research in natural sciences, it was overlooked that nanoparticles were already known since a much longer time (e.g. micelles, liposomes) and that they also occur naturally (in milk, blood, duodenum, etc.).

Since the newly developed nano-materials were unknown and the use of nanoparticles was launched as a hype, raising unrealistic expectations regarding new medical therapies, soon warnings on the medical, dietetic and cosmetic use of such particles came up, simply because of the lack of information on the toxicology of these unknown materials in the nano-size range. Unfortunately, also nanoparticles with decade-long records of safe use and proven existence in nature and food were linked with this way of thinking and consideration, primarily by not very well-informed scientists, as potentially toxic. Nowadays, neither the EU nor the US-FDA gives a precise definition of nanotechnology. They assess new products containing particles in the nano-range from a scientifically sound objective and a case-by-case risk-benefit evaluation, based on careful and when needed extensive characterization and toxicity testing of the nano-sized particles. The US-FDA makes very clear that (nano-sized) lipid carriers belong to the class of flexible, biodegradable particles which upon administration onto the skin penetrate into the skin and fall apart in the skin [1]. Compared to the other class of nanoparticles comprising solid nano-sized particles, which do not fall apart, there is no risk of systemic absorption and systemic toxicity of these lipid carriers.

In cosmetic products, phospholipids are popular as biodegradable natural ingredients. They can be used in classical formulations like suspensions, oil-in-water and water-in-oil emulsions and mixed micelles. These formulation 
types can be made or have particle sizes which lie in the range of nanoparticles. Based on the point of view of the US-FDA, the question can be raised whether the particle size of such lipid carriers, having a particle size in the nano-range (liposomes, oil-in-water nano-emulsions), will influence the degree of skin interaction. The skin distribution and penetration of lipid particles varying in size and composition have been studied primarily in pharmaceutical research. Mainly, liposomes or liposomes with commercially attractive names like "invasomes" [2] and "transfersomes" [3] suggesting powerful permeation properties were investigated. Liposomes were primarily of interest due to their intriguing cell-like structure, enabling the encapsulation of water-soluble drugs which needed to be transported through the skin to achieve transdermal delivery and systemic therapy. It is now generally understood that intact liposomes (flexible or not) are not able to pass the skin to any significant extent [4] but are excellent carriers to enhance the skin interaction of co-formulated compounds in cosmetic products. The results and status of this (pharmaceutical) research and the relevance for cosmetic use and resulting knowledge on the skin interaction of the phospholipids and delivery of compounds of cosmetic interest to the skin are described and discussed below.

\subsubsection{Phospholipid Properties}

The phospholipid molecule comprises a glycerol backbone which is esterified in positions 1 and 2 with fatty acids and in position 3 with phosphate. The systematic designation of, e.g., phosphatidic acid (PA) is 1,2-diacyl-sn-glycero-3-phosphate (where $s n$ means 'stereospecific numbering'). The specific and non-random distribution of substituents over the positions 1, 2 and 3 of the glycerol molecule introduces chirality. In typical membrane phospholipids, the phosphate group is further esterified with additional alcohol, for instance in phosphatidylcholine (PC) with choline (Fig. 6.1), in phosphatidylethanolamine (PE) with ethanolamine, in phosphatidylglycerol (PG) with glycerol and in phosphatidylinositol (PI) with inositol. The

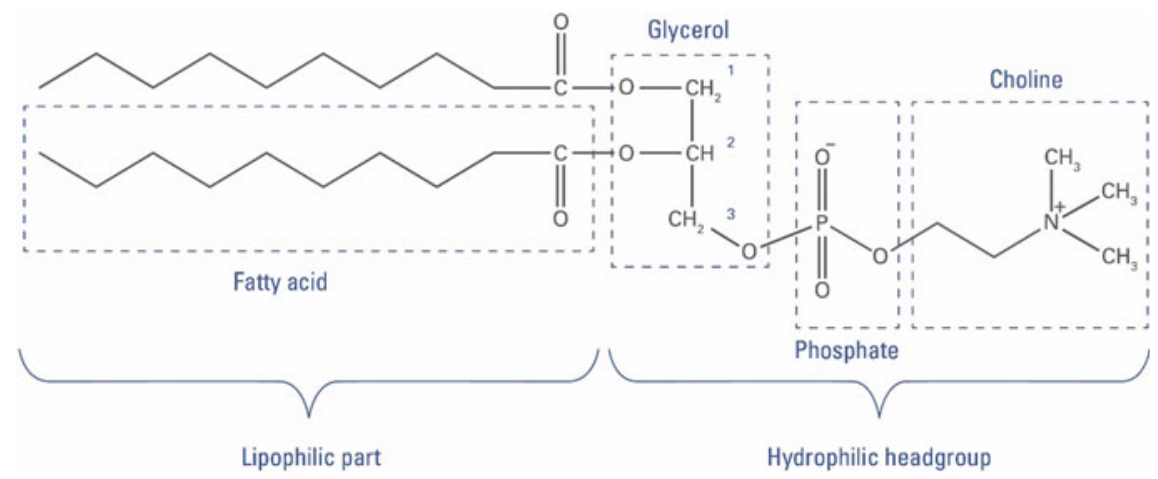

Fig. 6.1 Molecular structure of phosphatidylcholine 
phospholipid without esterified alcohol is phosphatidic acid. Depending upon the structure of the polar region and $\mathrm{pH}$ of the medium, PE and PC are zwitterionic and have a neutral charge at $\mathrm{pH}$ values of about 7 , whereas, e.g., PG is negatively charged.

The molecular structure of phospholipids comprises a hydrophilic part and a lipophilic part and has therefore a particular amphiphilic character. After mixing with an aqueous phase, they are able to form various structures depending on the number and type of fatty acids esterified to the glycerol backbone and the ratio of the surface areas occupied by the hydrophilic and lipophilic part of the phospholipid molecule. Diacylphospholipids having a cylindrical shape are organized as lipid bilayers (lamellar phase) with the hydrophobic tails lined up against one another and the hydrophilic head group facing the water on both sides (Fig. 6.2). The structures then formed are called liposomes. The bilayer membrane of such a liposome resembles the basic structures of cellular membranes. Because of this similarity, it is therefore evident that phospholipids are biocompatible and may have a beneficial interaction with skin cells.

\section{Species}

Phosphatidylcholine

Phosphatidylserine

Phosphatidylinositol

Sphingomyelin

Dicetylphosphate
Shape

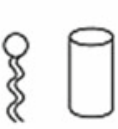

Cylinder
Organization

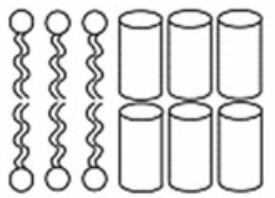

Bilayer
MPMPMPMPMPMP

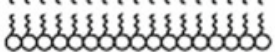

mPMPmpmpmpmp sussussusususususus

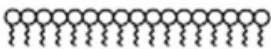

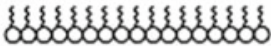

Lamellar phase

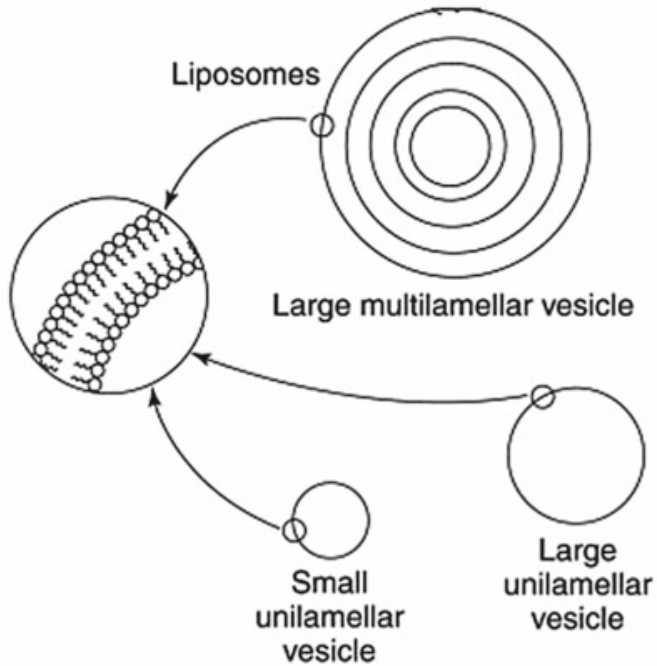

Fig. 6.2 Phospholipid molecules with a cylindrical shape which form upon hydration phospholipid bilayers and liposomal structures. Adapted from Lasic [5] 


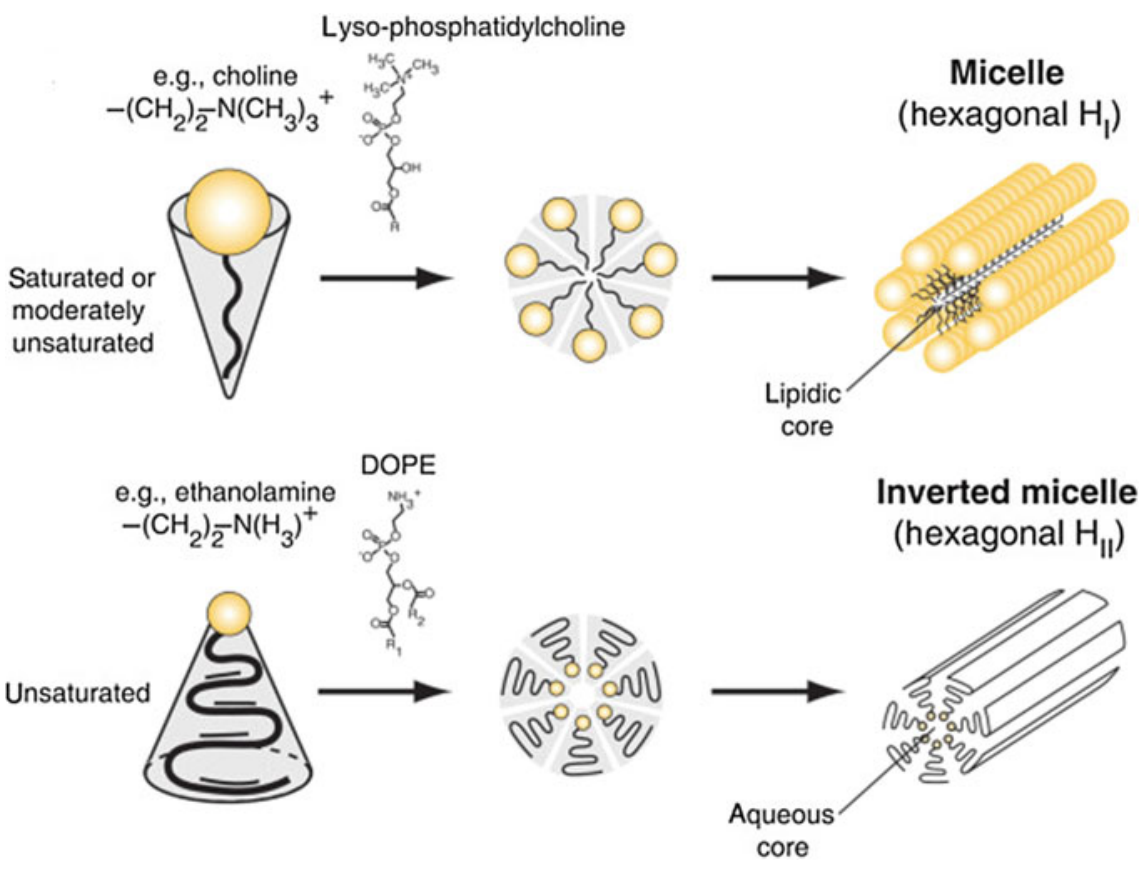

Fig. 6.3 Phospholipid molecules with either cone shape (above) or inverted cone (below) shape, forming upon hydration micelles or inverted micelles, respectively. Adapted from Kraft et al. [6]

When only one fatty acid is esterified to the glycerol backbone of the phospholipid molecule (monoacylphospholipids, also called lyso-phospholipids), and the polar head group are relatively large, the molecules are cone-shaped, and they can form micelles (also called hexagonal $\mathrm{H}_{\mathrm{I}}$ phase). An example of such a phospholipid is lysophosphatidylcholine. When the surface area of the polar head group is small (e.g. in case of phosphatidylethanolamine) compared to the surface area of the fatty acid part, then so-called inverted cones are formed which are upon hydration arranged in the so-called $\mathrm{H}_{\mathrm{II}}$ phase (Fig. 6.3).

The fatty acid composition of phospholipids determines the temperature at which the fatty acids change their mobility. Below the temperature of the phase transition from the liquid crystalline to the so-called gel state, the fatty acids and the phospholipid molecule are rigid (gel state), whereas above this phase transition temperature the fatty acids and the phospholipid molecule are mobile (Fig. 6.4).

Phospholipids with polyunsaturated fatty acids have a very low (below $0{ }^{\circ} \mathrm{C}$ ) phase transition temperatures. This means that at skin temperatures of around $32^{\circ}$ $\mathrm{C}$, these lipids are in the liquid crystalline state and form, upon hydration, structures/liposomes with a flexible membrane. Phospholipids with unsaturated fatty acids can be converted by means of hydrogenation to phospholipids containing saturated fatty acids. Hydrogenated soybean PC (HSPC) is an example of a saturated phospholipid, which contains mainly saturated fatty acids. The fatty acid 
Gel State Liquid Crystalline State

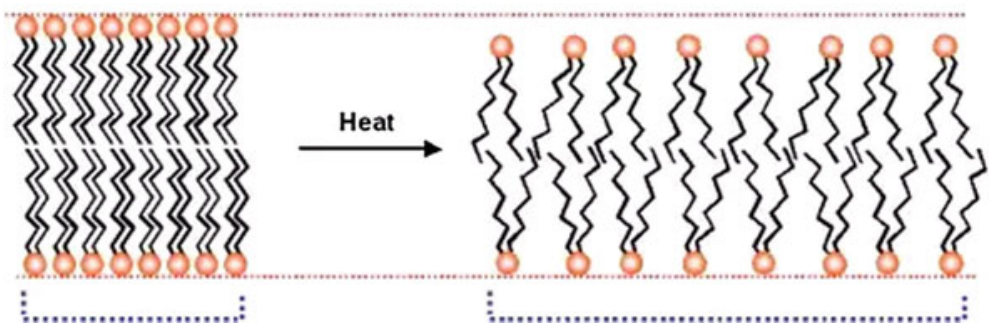

Fig. 6.4 Structures of phospholipid in the gel or liquid crystalline state. Adapted from Blaber [7]

composition is then approximately $85 \%$ stearic acid, $14 \%$ palmitic acid, and $1 \%$ other saturated fatty acids. The phospholipids with these saturated fatty acids have a high phase transition temperature of approximately $55^{\circ} \mathrm{C}$. At skin temperatures, liposomal dispersions with hydrogenated lipids are therefore in the gel state and rigid in nature.

The moisturizer effect of phospholipids on the skin is explained by their excellent skin interaction and their hygroscopic properties, as demonstrated in the following experiments. Figure 6.5 shows the hygroscopicity of unsaturated soybean phosphatidylcholine and saturated soybean phosphatidylcholine (data kindly provided by Lipoid GmbH, Germany).

Figure 6.5 shows that unsaturated soybean phosphatidylcholine is slightly more hygroscopic than saturated soybean phosphatidylcholine. At $25 \% \mathrm{RH}$ and $30{ }^{\circ} \mathrm{C}$, the mass increase of unsaturated soybean phosphatidylcholine by hydration is limited to only $3 \%$ after $5 \mathrm{~h}$. The saturated soybean phosphatidylcholine is under these conditions not hygroscopic. When soybean phospholipids are processed in dry form or into dry formulations, the humidity and temperature of the production environment should therefore be controlled, and preferably the humidity should be $25 \% \mathrm{RH}$ at $30{ }^{\circ} \mathrm{C}$ or lower. In general, dry phospholipids can absorb up to $12 \%$ by weight water; this represents about five molecules of water bound to one molecule of phospholipid. In case phospholipids are fully hydrated in the form of liposomes, they can bind 20 molecules of water per phospholipid molecule [9].

Unsaturated phospholipids may have a yellowish/brownish color, especially when considering lower purity grade fractions. Higher grade fractionated phospholipids of, e.g., soybean phosphatidylcholine are yellowish in color. Hydrogenated (saturated) phospholipids have a white color. The odour of phospholipids is slightly nutty. When needed, addition of fragrances can easily mask this odour.

Natural phospholipids used in cosmetics are mainly coming from soybeans, sunflower seed or rapeseed. Sunflower phospholipids are considered to be non-GMO; soybean and rapeseed (canola seed) phospholipids can be supplied in a non-GMO quality as well. Synthetic phospholipids are hardly being used by the cosmetic industry [10]. 

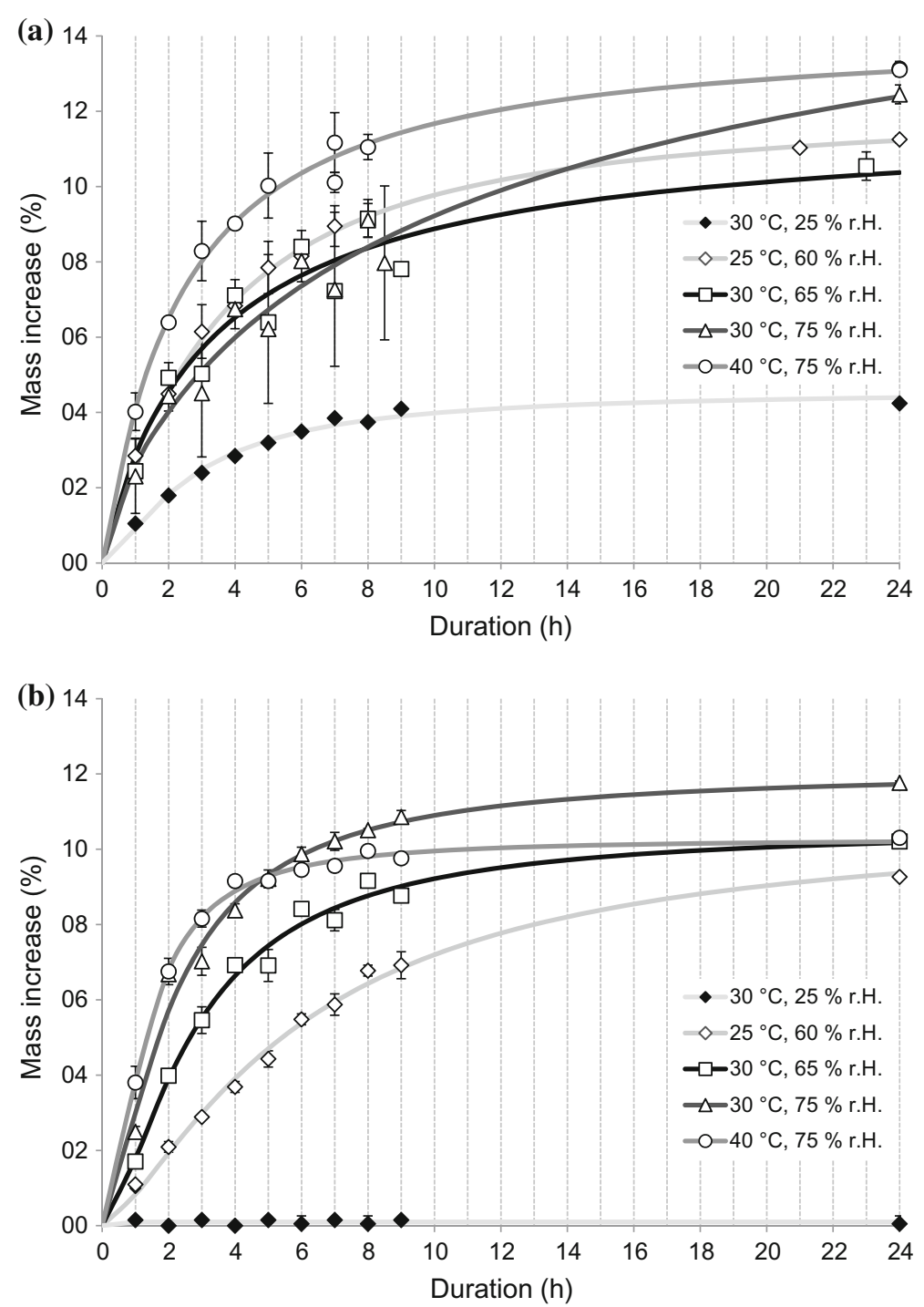

Fig. 6.5 Hygroscopicity of a unsaturated soybean phosphatidylcholine with n.l.t. 94\% PC and b saturated soybean phosphatidylcholine with n.l.t $90 \%$ PC, as determined according to Yee and Davis [8]

In the literature on the application of phospholipids in cosmetics, there is some confusion on the use of the terms lecithin and phosphatidylcholine. This is because in the American literature, "lecithin" is used as a synonym for phosphatidylcholine, whereas according to generally accepted pharmacopeial definitions lecithin is the complex mixture of acetone-insoluble phosphatides (i.e. phospholipids), from 
vegetable source. This "consists chiefly of phosphatidylcholine, phosphatidylethanolamine, phosphatidylinositol and phosphatidic acid, present in conjunction with various amounts of other substances such as triglycerides, fatty acids, and carbohydrates, as separated from the crude vegetable oil source" [11]. For this reason, it is proposed to use "lecithin" to describe a product when it contains less than $80 \%$ by total weight phospholipids (and phosphatidylcholine as main component). Products containing, e.g., 80-90\% of phospholipids from soybean can be called soybean phospholipids. Purified phospholipid fractions containing more than $90 \%$ by weight of phosphatidylcholine shall be designated as "phosphatidylcholine". In the description of the discussed phospholipid products in this manuscript, the weight percentage of phosphatidylcholine in these products is indicated.

\subsubsection{Phospholipids Raw Materials}

In cosmetic products, lecithins containing varying amounts of phosphatidylcholine and unsaturated and saturated diacylphosphatidylcholines, and to a lesser extent monoacylphospholipids (lysolecithins), are used. The phosphatidylcholine content of the lecithins can be enriched using fractionation methods like solvent extraction and chromatography. After fractionation, several grades can be produced starting to form crude lecithin containing ca. 15\% PC still comprising significant amounts of the plant oil raw material from which it has been isolated, and de-oiled or fractionated lecithin to obtain higher contents of PC from 25 to $96 \%$. Phospholipids are essential natural components of the membrane of all living cells; they are non-toxic and possess very high skin tolerability.

The purified phospholipids have a typical fatty acid composition related to the plant source used. The fatty acid composition of soybean phosphatidylcholine can be found in Table 6.1.

As described above, phospholipids containing polyunsaturated fatty acids have a very low (below $0{ }^{\circ} \mathrm{C}$ ) phase transition temperature. At skin temperatures of around $32{ }^{\circ} \mathrm{C}$, these lipids are therefore in the liquid crystalline state and form, upon hydration, very flexible structures/liposomes.

Table 6.1 Fatty acid composition (mole \%) of soybean phosphatidylcholine determined by enzymatic hydrolysis followed by gas chromatography [12]

\begin{tabular}{l|l|l|l}
\hline Fatty acid & In 1-position (\%) & In 2-position (\%) & Total (\%) \\
\hline Palmitic acid (C16:0) & 24.0 & 1.7 & 12.9 \\
\hline Stearic acid (C18:0) & 7.9 & 1.0 & 4.4 \\
\hline Oleic acid (C18:1) & 10.9 & 10.0 & 10.5 \\
\hline Linoleic acid (C18:2) & 52.4 & 80.6 & 66.5 \\
\hline Linolenic acid (C18:3) & 4.7 & 6.7 & 5.7 \\
\hline
\end{tabular}




\subsection{Skin Structure}

In order to understand the interaction of phospholipids with the skin, the physiology of the epidermis, including the stratum corneum, the skin layer relevant for cosmetic treatment and the presence of (endogenous) phospholipids in these layers will be reviewed in the first instance (Fig. 6.6).

The stratum corneum is the target skin layer for cosmetic products. It is the utmost significant barrier of the epidermis, even that it is not thicker than a sheet of paper. Without stratum corneum, the human body would lose every day about 201 of water in contrast to 0.151 per day with an intact stratum corneum. The structure of the stratum corneum is best described in short with the classic "brick-and-mortar model" [13]. The corneocytes represent the bricks and the intercellular lipids, in which the corneocytes are embedded, the mortar. The thickness of this barrier varies depending on variables like individual persons, gender and body region between 6 and $40 \mu \mathrm{m}$, a body "average" thickness for four areas (abdomen, flexor forearm, thigh and back) being estimated as 8.7-12.9 $\mu \mathrm{m}$ [14]. The number of corneocyte layers is correspondingly higher at thicker stratum corneum (14-23 layers) [14]. Some studies indicate that the "brick-and-mortar" wall indeed seems to have narrow channels [15] or small pores varying from $0.59 \mathrm{~nm}$ [16], to about $3.6 \mathrm{~nm}$ [17] and up to $20 \mathrm{~nm}$ [18]. Please note that these measurements were made with stratum corneum of different species and most values are obtained by various and indirect

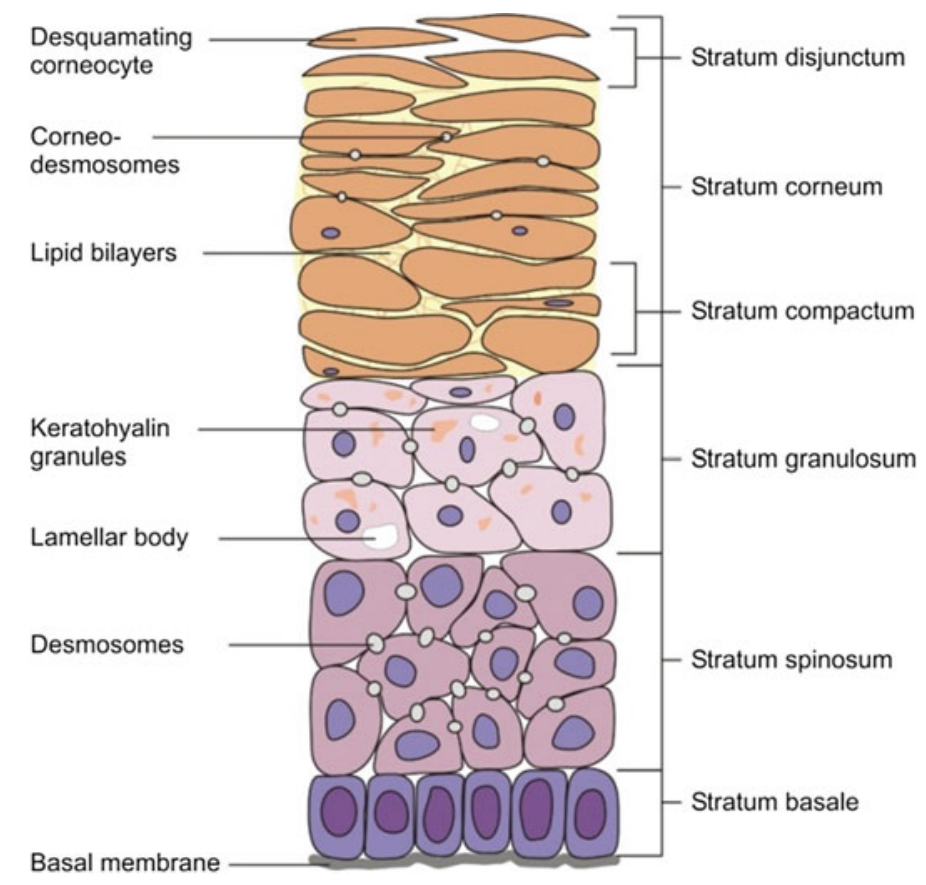

Fig. 6.6 Structure of the human skin layers, relevant for treatment with cosmetic products 
methods. However, these structural data are crucial for the still ongoing discussion, if and how colloidal systems containing phospholipids may penetrate intact the stratum corneum (see Sects. 6.5.3 and 6.7).

The epidermis is a very dynamic system; in about four weeks, the epidermis is renewed in younger humans. However, at the age of 60 years this time is doubled. The stratum corneum itself is being considered as "dead", as the corneocytes do not show metabolism and have lost their nucleus.

The renewal of the stratum corneum starts at the border between epidermis and dermis, the stratum basale. The stratum basale consists of a layer of elongated basal cells which rest on the basement membrane. These basal cells are connected via desmosomes and are continuously proliferating. These newly produced cells are called keratinocytes (which can again divide themselves 4-5 times) and delaminate from the stratum basale still connected to their surrounding neighbours via desmosomes. They migrate into the stratum spinosum. The name was attributed to their spiny appearance.

The keratinocytes migrate from this point to the stratum granulosum (named after the granular appearance of the cytoplasm). These keratinocytes start to produce in their cytosol so-called lamellar bodies, which contain a variety of lipids and enzymes (see details below). Also keratohyalin granules are provided by the keratinocytes in the stratum granulosum, which contain precursor proteins for the keratin core of the finished corneocytes. At the transition between stratum granulosum and stratum corneum, the lamellar bodies (also called "Odland bodies") are excreted. This results not only in the formation of the intercellular lipid matrix, but also of a hydrophobic lipid envelope. This corneocyte lipid envelope (CLE) (see, e.g., [19]) is a monolayer of covalently bound $\omega-\mathrm{OH}$-ceramides to the surface of the developing corneocytes which allow the embedding of the hydrophilic corneocytes into the intercellular hydrophobic matrix. Also proteins are cross-linked in this envelope and make the corneocyte envelope even tighter [20]. This whole envelope structure reduces absorption of substances into the corneocytes. For these reasons, most of the active substances applied onto the skin are diffusing along the lipid lamellae in the intercellular regions. During migration closer to the stratum corneum region, the keratinocytes start to become non-viable corneocytes by losing DNA, RNA and almost all organelles.

The stratum compactum is the tightest part of the stratum corneum, which is also due to the corneodesmosomes (successor of the desmosomes) which keep the corneocytes together. These corneosomes are hydrolysed closer to the skin surface, as this is necessary for the desquamation at the surface and to be shed from the skin surface (exfoliation) to maintain homoeostasis.

There is a pronounced $\mathrm{pH}$ gradient across the stratum corneum, starting at the skin surface with $4.5 \pm 0.2$ for men and $5.3 \pm 0.5$ for women at the volar forearm [21]. After complete removal of the stratum corneum by stripping, a $\mathrm{pH}$ of $6.9 \pm 0.4$ is measured for men and $6.8 \pm 0.5$ for women [21]. This means a $\mathrm{pH}$ change of 2 units over a distance of about $10 \mu \mathrm{m}$ ! The acidified skin surface functions as a deterrent to skin infections by, e.g., inhibiting skin colonization with Staphylococcus aureus or Streptococcus pyogenes [22, 23]. 


\subsection{Skin (Phospho)lipids}

Lipids play a decisive role in creation and maintaining the barrier function of the stratum corneum. During the conversion of keratinocytes to corneocytes and the migration to the top of the skin, a tremendous activity of anabolism and catabolism of lipidic material is going on. For a better understanding, a schematic drawing of the prominent metabolic pathways is depicted in Fig. 6.7. There are many more reactions involved (see, e.g., [24]), but this is beyond this review.

These metabolic activities are in the healthy skin in steady state. The enzymes and the (phospho)lipid concentrations in the different regions of the epidermis have been determined in numerous studies.

Type I secretory phospholipase $\mathrm{A}_{2}\left(\mathrm{sPLA}_{2}\right)$ activity in tape strips of human skin could be detected [26]. In the tape strips taken from the skin surface (strips 1-10), activity of $1 \mathrm{mU} / \mathrm{mg}$ protein was obtained; in the lower region, a threefold higher activity was observed. Immuno-histochemical staining of skin slices with anti-porcine pancreatic sPLA 2 revealed the primary location of $\mathrm{sPLA}_{2}$ at the stratum corneum-stratum granulosum junction. This supports the notion raised earlier [27] that $\mathrm{sPLA}_{2}$ hydrolyses the phospholipids secreted from lamellar bodies and serves as producer of specific fatty acids improving thereby the barrier properties of the stratum corneum and acidifying the upper part of the stratum corneum. In this

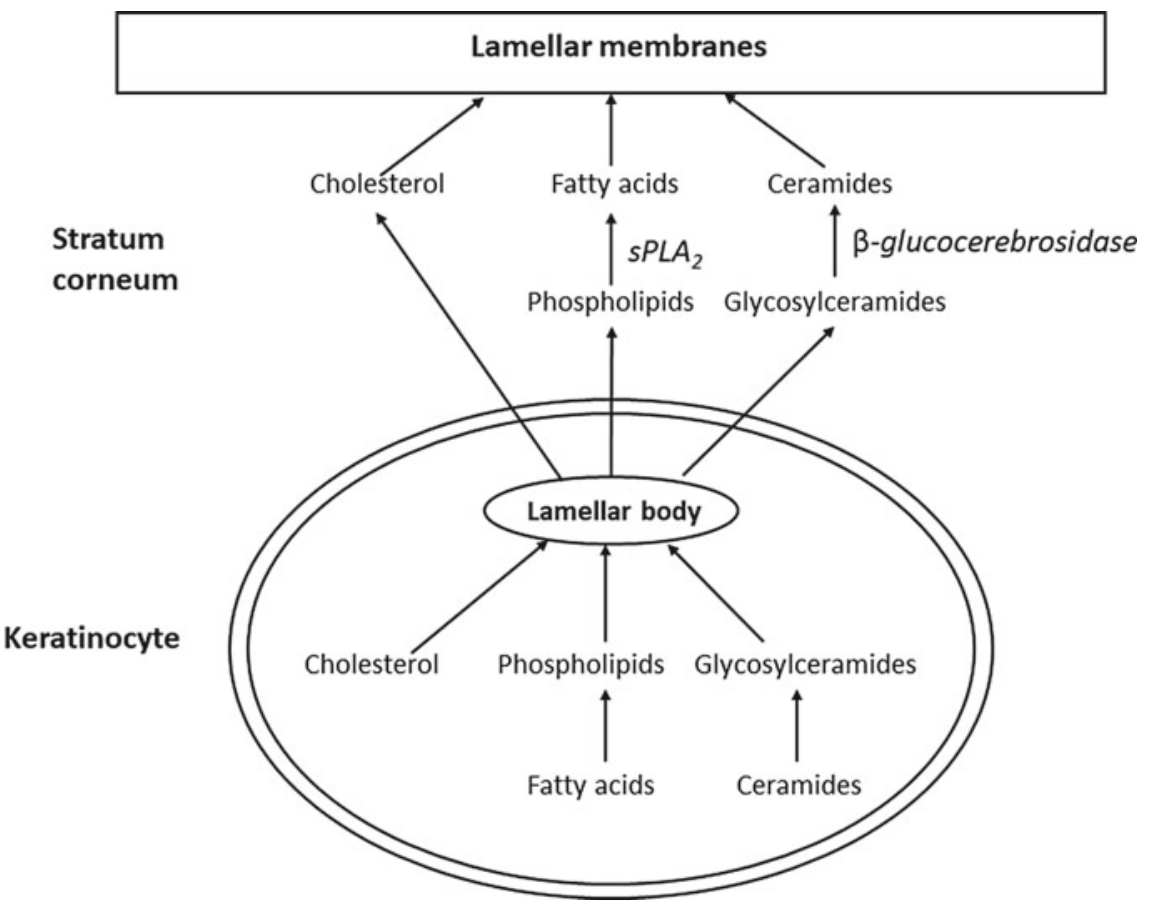

Fig. 6.7 Metabolic processes in the upper epidermis. Modified after Feingold [25] 
earlier study [27] done in mice, the putative $\mathrm{SPLA}_{2}$ was blocked by bromophenacyl bromide and MJ-33, which reduced the fatty acid content in the upper stratum corneum layers and caused thereby a perturbation of the barrier function, and epidermal hyperplasia. This defect could be reversed by topical application of free or esterified to phospholipids fatty acids. This also proved that the barrier impairment is not caused by the accumulation of phospholipids in the upper layer of the stratum corneum. Besides enzymatic degradation by means of PLA 2 , phospholipase D may also play a role [9].

As one of the consequences of the phospholipase activity in the stratum corneum, the phospholipid percentage of the lipid composition decreases dramatically from the basal layer (about $50 \%$ ) to the stratum corneum $(<5 \%)$, as can be seen in Fig. 6.8, and the fatty acid content in the stratum corneum significantly increases. Similar distributions of phospholipids were found in pig skin [28], but here the phospholipid content gradient was not as pronounced between stratum corneum and viable epidermis $(2.5 \mathrm{mg} / \mathrm{g}$ tissue vs. $10 \mathrm{mg} / \mathrm{g}$ tissue, respectively).

As a widely used rule of thumb, the major intercellular lipid composition of the stratum corneum is given as consisting of about $50 \%$ ceramides, $25 \%$ cholesterol, $10 \%$ fatty acids, cholesterol sulphate and esters [30]. These lipids form bilayers with a thickness of 4-5 nm. A particular group of ceramides contains a C36-side chain, which extends into the neighbouring bilayer, thereby "nailing" them together.

The overall lipid composition of the stratum corneum varies with regions of the body. The first investigation on human stratum corneum [31] showed a significant variation of the neutral lipid content (see Table 6.2). This neutral lipid group

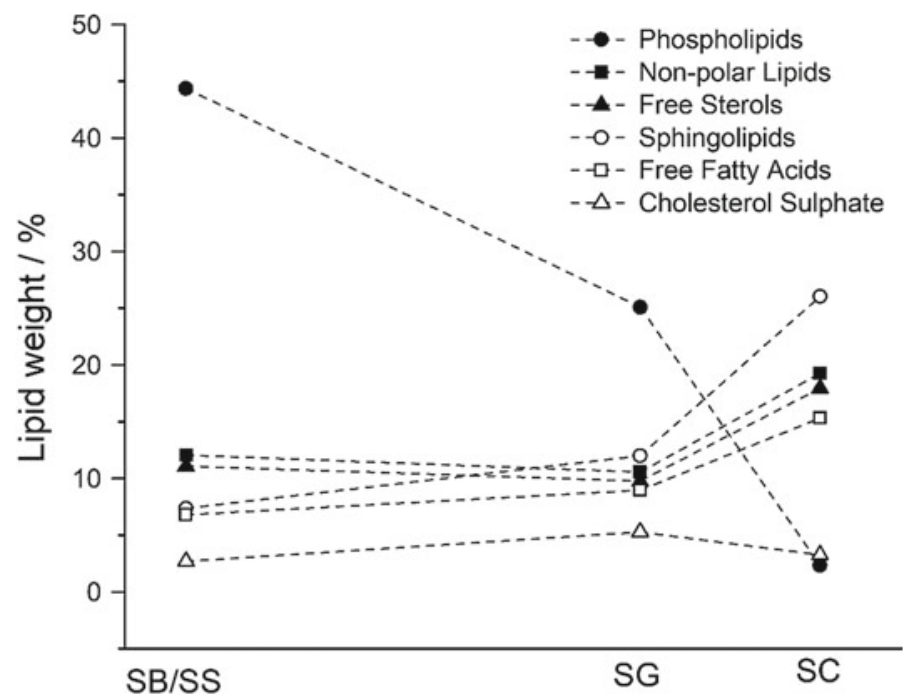

Fig. 6.8 Stratification of lipid species in human epidermis, redrawn after Lampe et al. [29]; SB/SS - stratum basale, stratum spinosum; SG — stratum granulosum; SC - stratum corneum 
Table 6.2 Regional variations in lipid weight per cent and distribution of significant lipid species in the stratum corneum; values in weight percent

\begin{tabular}{l|l|l|l|l}
\hline Lipid fraction & Face & Abdomen & Leg & Plantar \\
\hline Phospholipids & 3.3 & 4.9 & 5.2 & 3.2 \\
\hline Glycosylceramides & 6.7 & 2.6 & 3.4 & 6.4 \\
\hline Cholesterol sulphate & 2.7 & 1.5 & 6 & 3.4 \\
\hline Free fatty acids & 19.7 & 19.3 & 13.9 & 9 \\
\hline Ceramides & 19.9 & 15.5 & 22.6 & 28.4 \\
\hline Free sterols & 17.3 & 14 & 20.1 & 32.8 \\
\hline Triacyl glycerols & 13.5 & 25.2 & 20.1 & 5.9 \\
\hline Sterol esters & 6.2 & 6.1 & 4.6 & 7.1 \\
\hline Squalene & 6.9 & 6.5 & 3.6 & 2.9 \\
\hline n-alkanes & 2.8 & 3.7 & 3 & 2.9 \\
\hline Adapted fram & & & &
\end{tabular}

Adapted from Lampe et al. [31]

comprising free sterols, free fatty acids, triglycerides, sterol and wax esters, squalene and $\mathrm{n}$-alkanes dominates the lipid content of the stratum corneum. The phospholipid content varied according to this study not statistically significant (3.2$5.2 \%$ weight of total lipid weight).

Concentration values for the gradient of lipid classes across the stratum corneum [32] were measured. The gradient was quite significant for free fatty acids, for which the fatty acid content decreased from $6.5 \mu \mathrm{g} / \mathrm{cm}^{2}$ starting at the surface to $3.0 \mu \mathrm{g} / \mathrm{cm}^{2}$ in the lower parts of the stratum corneum. A decrease in ceramides and cholesterol from the surface to the lower parts was statistically significant as well. A peculiar gradient profile was found for phospholipids, as the phospholipid content at the surface and the basal site of the stratum corneum are quite low (2.5 and $3 \mu \mathrm{g} / \mathrm{cm}^{2}$ respectively), but at about the lower third a higher content of $5.5 \mu \mathrm{g} / \mathrm{cm}^{2}$ was found. This might be due to the synthesis of phospholipids in this layer of the stratum corneum (see Fig. 6.7).

The fatty acid composition of the few detected phospholipids in stratum corneum comprised of 18:0, 18:1 and 18:2 fatty acid chains, which reflects the fatty acid composition of the viable epidermis phospholipids [29] coarsely. In contrast to that, 16:0 fatty acid chains that were present to $26 \%$ in the phospholipids of the viable epidermis were only present to $2.8 \%$ in the phospholipids of the stratum corneum. It has to be emphasized that neither phospholipids nor glycosphingolipids are present [29] in the outer layers of the human stratum corneum (stratum disjunctum).

To the knowledge of the authors, very little is known regarding which specific phospholipid enzymes, involved in the anabolic construction of phospholipids, are expressed in the epidermis. Additionally, the regulation of phospholipid synthesis in the epidermis has not been delineated. Further studies in this area are clearly needed, given the requirement for phospholipids for the formation of lamellar bodies, and as sources of free fatty acids, and for the low $\mathrm{pH}$ of the stratum corneum. 
Finally, one example should accentuate the rather complex interplay between skin region, cells, lipids and metabolism. Lipids are secreted at the stratum granulosum-stratum corneum interface into an extracellular environment at neutral $\mathrm{pH}$. Initial processing of the lipid bilayers into elongated, fused sheets is performed by enzyme(s) with a neutral $\mathrm{pH}$ optimum, such as the secretory phospholipase $\mathrm{A}_{2}$. As the partially processed lipids migrate upward, the extracellular environment becomes progressively more acidic, activating $\beta$-glucocerebrosidase, and perhaps other enzymes with an acidic $\mathrm{pH}$ optimum, allowing the final processing step into mature lamellar multilayers (cited from Mauro et al. [33]).

All the mentioned studies prove that the stratum corneum is not a homogeneous matrix in itself; it instead forms a very heterogeneous structure and contains besides corneocytes and multilamellar lipid layers a variety of other biologically active substances. They are also interacting complexly, including the migration dynamics and gradients like $\mathrm{pH}$ and enzyme activities. The understanding of these mechanisms is just beginning to grow, despite the fact that skin (and especially the stratum corneum) is readily available for research, as it is situated at the outside of our body and samples are easy to obtain.

\subsection{Phospholipid Skin Toxicity/Tolerance}

It is widely documented that phospholipids (lecithin and hydrogenated lecithin) are well-tolerated when administered to the skin [34]. Also, the US Cosmetic Ingredient Review (CIR) organization qualifies lecithin as safe as used [35]. In this safety assessment, the used concentrations of phospholipids in various commercially available products and cosmetic uses are described.

In order to confirm the high degree of skin compatibility of selected commercially available phospholipid products, the skin tolerability of various phospholipids was investigated by means of the HET-CAM (Hen's egg test on chorioallantoic membrane) test (data kindly provided by IADP (An-Institut für angewandte Dermatopharmazie, Halle (Saale) Germany), an in vitro model with chicken eggs to assess skin and ocular irritation potential. A 30\% dispersion of the phospholipids in medium-chain triglycerides (MCT), which are well-tolerated in dermal and cosmetic products, was used [36]. The tested 30\% dispersions of the phospholipids were ten times higher than previously tested [34] and appeared to be sufficiently transparent, allowing the more sensitive reaction-time method to assess the irritation potential. The eggs ( $n=6$ per test solution) were observed for $300 \mathrm{~s}$, the changes of the morphology of the CAM were photographically documented and qualitatively assessed, also the occurrence of haemorrhages, lysis of veins and occurrence of blood coagulation (Table 6.3). Controls were $0.9 \% \mathrm{NaCl}$ (non-irritating control) and $1-2 \%$ SDS (irritating control). 
Table 6.3 Irritation potential of examples of phospholipid products in the HET-CAM test; $(\mathrm{H})$ occurrence of haemorrhages, (L) lysis of veins (C) and occurrence of blood coagulation

\begin{tabular}{l|l|l|l|l}
\hline Test product & H & L & C & Irritation potential \\
\hline $\mathrm{NaCl}(0.9 \%)$ & - & - & - & No \\
\hline $\mathrm{SDS}(1 \%)$ & Yes & - & - & Yes \\
\hline $\mathrm{SDS}(2 \%)$ & Yes & - & - & Yes \\
\hline $\mathrm{MCT}$ & - & - & - & No \\
\hline Soybean lecithin $45^{\mathrm{a}}$ & - & - & - & No \\
\hline Sunflower lecithin 50 & - & - & - & No \\
\hline Canola lecithin 50 & - & - & - & No \\
\hline Soybean lecithin (IP) 50 & - & - & - & No \\
\hline Soybean lecithin (IP) 75 & - & - & - & No \\
\hline Soybean lecithin 75 & - & - & - & No \\
\hline Egg phospholipids 80 & - & - & - & No \\
\hline Soybean phospholipids 80 & - & - & - & No \\
\hline Egg phosphatidylcholine 98 & & & & No \\
\hline Soybean phosphatidylcholine (IP) 98 & - & - & - & No \\
\hline Soybean phosphatidylcholine 98 & - & - & - & No
\end{tabular}

${ }^{a}$ The number indicates the content of phosphatidylcholine in the product

Eggs treated with 1-2\% SDS showed changes of blood vessels like hyperaemia and bleeding [compare Fig. 6.9, $n$ (before treatment) and $n^{*}$ (after treatment)], as was expected. In spite of interference with the observations caused by film formation and color of the products, all tested phospholipid products showed, even tested with a $30 \%$ concentrated dispersion of egg phosphatidylcholine with $98 \%$ $\mathrm{PC}$, the same lack of irritation potential as the non-irritating control with $0.9 \% \mathrm{NaCl}$ and the used solvent MCT. Examples of the test results are provided in Fig. 6.9.

To further confirm the high degree of skin compatibility of selected commercially available phospholipid products, the following IQ ULTRA ${ }^{\circledR}$ occluded patch test, using $68 \mathrm{~mm}^{2}$ polyethylene plastic moss chambers with incorporated filter paper soaked with lipid test solution or controls, was performed on volunteers (data kindly provided by Lipoid GmbH, Ludwigshafen, Germany). One patch test consisted of ten chambers that were fixed on the back of the test person with a hypoallergenic non-woven adhesive tape (see Fig. 6.10).

The filter papers were saturated with $0.02 \mathrm{ml}$ of a $10 \%$ aqueous dispersion of the lecithin, phospholipid or emulsifier, respectively. The patches were in contact with the skin once for $48 \mathrm{~h}$ (48-hour occluded patch test). An empty patch was applied as "negative" control. 

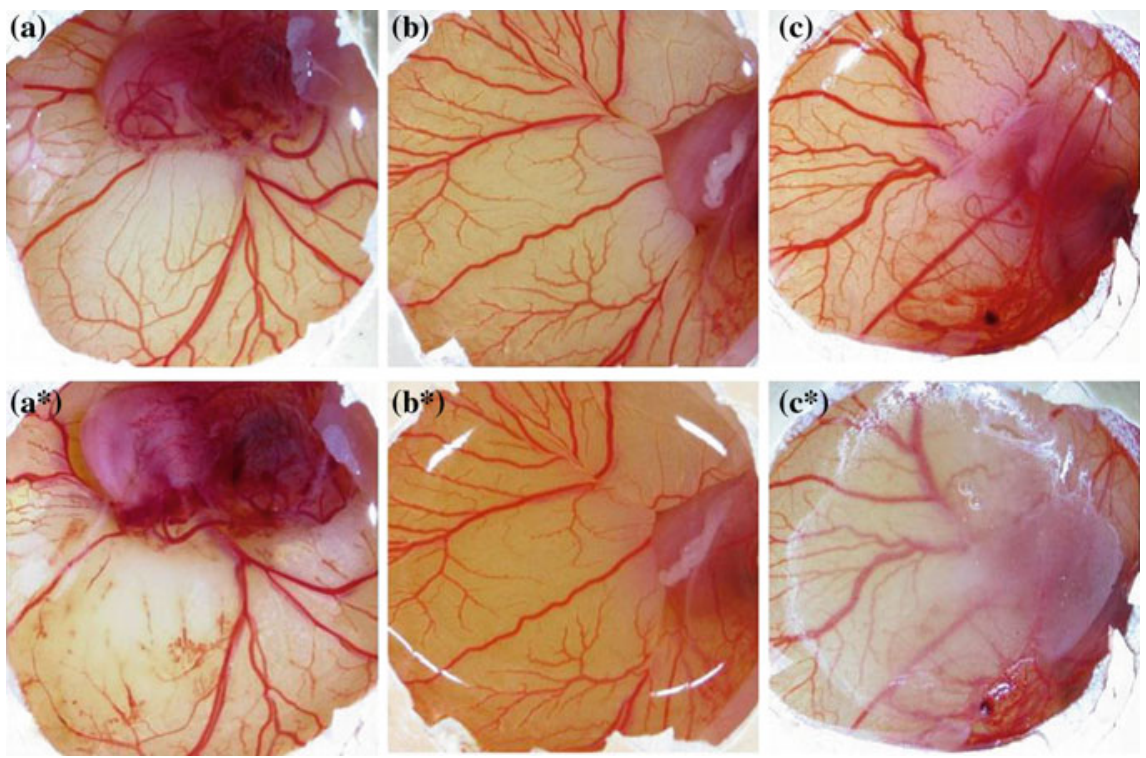

Fig. 6.9 Photographs of HET-CAMs before (n) and after application (n*) a SDS 1\%, b NaCl $0.9 \%$, c $30 \%$ aqueous dispersion of egg phosphatidylcholine with $98 \%$ PC
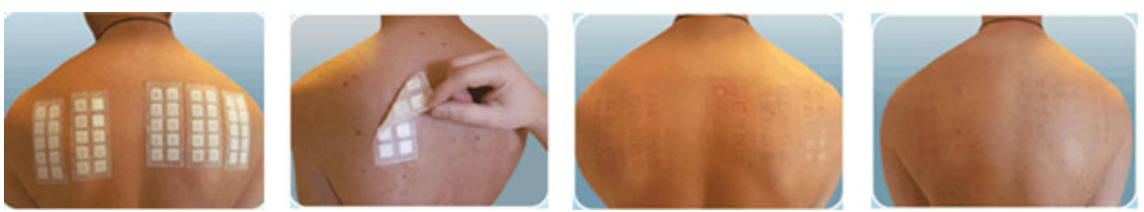

Fig. 6.10 Example of the performance of IQ ULTRA ${ }^{\circledR}$ patch test

The number of volunteers (female and male with healthy skin) was 22 or 24 , respectively, and included only persons with normal skin, aged 18-70 years. The contact zone on the back of the volunteers was examined just before starting the study in order to apply the products on a skin surface free from macroscopic irritation marks, scars or any abnormalities which could interfere with the interpretation of the results. The area on which the patch was applied was cleaned with deionized water and dried with cellulose cotton wool tissue. The test skin areas were not in contact with any cosmetic products before and during the test. Withdrawal of the patches and the readings were made by a dermatologist. 
The analysis of the skin reaction was performed for each volunteer, according to the following scale:

\begin{tabular}{l|l}
\hline Erythema & \\
\hline None & 0 \\
\hline Slight erythema, hardly noticeable & 1 \\
\hline Moderate and uniform redness & 2 \\
\hline Significant and uniform redness & 3 \\
\hline Dryness/desquamation & \\
\hline No dryness & 0 \\
\hline Dry with desquamation, smooth and stretched aspect, slight and & \\
\hline Slight desquamation & 1 \\
\hline Moderate desquamation & 2 \\
\hline Severe desquamation with large scales & 3 \\
\hline Oedema & \\
\hline None & 0 \\
\hline Slight & 1 \\
\hline Noticeable & 2 \\
\hline Significant & 3 \\
\hline Blister & \\
\hline None & 0 \\
\hline Slight & 1 \\
\hline Noticeable & 2 \\
\hline Significant & 3 \\
\hline
\end{tabular}

The obtained results were compared to those of the control zone. The "Primary Irritation Index" was calculated according to the following formula:

$$
\text { Primary Irritation Index }=\frac{\frac{\left(\sum \text { Marks after } 48 \text { Hours }\right) \text { Volunteer } 1 \text { to } n}{\text { Number of Readings }}}{\text { Number of Volunteers }}
$$

The classification of the irritation potential was performed according to the following scale (Table 6.4).

Table 6.4 Classification of the irritation potential

\begin{tabular}{l|l}
\hline Primary irritation index & Classification \\
\hline $0-0.08$ & Non-irritant \\
\hline$>0.08-0.16$ & Very slightly irritant \\
\hline$>0.16-0.56$ & Slightly irritant \\
\hline$>0.56-1.0$ & Moderate irritant \\
\hline$>1.0-1.6$ & Irritant \\
\hline$>1.6$ & Very irritant \\
\hline
\end{tabular}


Table 6.5 Results of the 48-hour occluded patch test performed with examples of commercially available phospholipid products

\begin{tabular}{l|l|l}
\hline Product description & Irritation index & Classification \\
\hline Soybean lecithin $50^{\mathrm{a}}$ & 0 & Non-irritant \\
\hline Soybean phosphatidylcholine 85 & 0.04 & Non-irritant \\
\hline Soybean phosphatidylcholine 90 & 0.04 & Non-irritant \\
\hline Hydrogenated soybean lecithin 80 & 0 & Non-irritant \\
\hline Hydrogenated phosphatidylcholine 90 & 0 & Non-irritant \\
\hline Rapeseed lysolecithin $20^{\mathrm{b}}$ & 0 & Non-irritant \\
\hline
\end{tabular}

${ }^{a}$ The number indicates the content of phosphatidylcholine or blysophosphatidylcholine in the product

In Table 6.5, the results of occluded patch test are provided. None of the investigated phospholipids show, under the used test conditions, any irritation potential.

Although the presented data and literature references suggest that phospholipids have no or a very low skin irritation potential, it should be realized that these findings have been made with specific in vitro models, not necessarily reflecting application on the human skin or in vivo settings with a limited number of volunteers (possibly not able to pick up skin reactions in sensitive individuals), using simple formulations ruling out synergistic effects with, e.g., (other) emulsifiers and/or actives. It is therefore recommended not to exceed the concentrations listed above and to test specific formulations separately.

The possibility that co-administration of phospholipids and (other) cosmetic actives, which generally do not permeate through the skin, will give rise to a systemic availability of the cosmetic active is negligible [4]. Even flexible liposomes do not permeate to a significant amount through the skin and cannot carry a (water soluble) encapsulated compound through the skin. In addition, as pointed out above, liposomes comprising unsaturated phospholipid tend to fall apart in the stratum corneum of the skin. Liposomes comprising saturated phospholipids do even have a lower tendency to penetrate into the skin. It can be assumed that other types of formulations like oil-in-water emulsions with phospholipids as emulsifier and a liquid oil phase will behave in the same way as flexible liposomes.

\subsection{Use}

Because of their chemical structure and physicochemical properties, the use of phospholipids in cosmetic formulations has several unique aspects. In the following, it will be apparent that phospholipids are not only technically useful surface-active ingredients, but they are also used as actives and used to enhance the skin interaction by means of deeper transport into the skin of other formulation components. The phospholipid which can be used for what purpose is dependent on 
the flexibility/rigidity of the phospholipids obtained at skin temperature. They can penetrate either deeper into the skin and enhance transport or they can support the barrier function of the skin. In the latter case, the phospholipids will keep the skin in healthy condition and can, therefore, be considered as cosmetic actives. These functional properties of phospholipids are the basis for the excellent skin tolerability of phospholipids [34, 37]. For these reasons, phospholipids are considered as multifunctional cosmetic ingredients and actives.

Phospholipids are particularly of interest for use in natural cosmetic products because certain qualities are certified as non-GMO materials and assessed as being genuinely natural by reputed organizations like Cosmetics to Optimize Safety (COSMOS).

In the following section, the multifunctional properties of phospholipids are discussed in detail. Firstly, the technical (functional) use of phospholipid in cosmetic formulations and secondly the use as cosmetic actives will be covered.

\subsubsection{Surface Active}

Due to their amphiphilic (hydrophilic as well as lipophilic) structure, phospholipids possess surface activity. They can be technically used in cosmetic formulations as an emulsifier, liposome/lamellar phase former, solubilizer or wetting agent.

\subsubsection{Emulsifier}

Diacylphospholipids are considered to be very mild detergents and excellent emulsifiers [38, 9]. After hydration of diacylphospholipid molecules which have a cylindrical shape, lamellar structures and/or liposomes are formed. For this reason, they do not emulsify oil with water spontaneously. Mechanical energy is needed to disrupt liposomal structures and simultaneously force the phospholipid molecules to position themselves at the oil-water interface. After applying mechanical energy (by means of stirring with, e.g., a rotor-stator mixer), very stable oil-in-water or water-in-oil emulsions/creams can be prepared. The diacylphospholipid emulsifiers can either be dissolved in the oil or dispersed in the water phase.

Monoacylphospholipids (lyso-phospholipids) form micelles upon dispersion in water. They are stronger detergents (cone-shaped) and require less mechanical energy for the preparation of oil-in-water emulsions because micelles are less stable compared to liposomes, and are in equilibrium with a much higher monomer concentration. Interestingly, products comprising diacyl- as well as monoacylphospholipids with about $60 \%$ lyso-PC form mixed micelles upon hydration and can be considered as intermediate mild emulsifiers, due to the presence of diacylphospholipids.

Published HLB values on phospholipid emulsifiers vary greatly and display a broad range, suggesting that they are suitable for the preparation of oil-in-water as well as water-in-oil emulsions using a large variety of oils differing in required HLB values $[39,40]$. The variety and variability of reported HLB values and ranges of especially natural phospholipids may be explained by the heterogeneity in the 
composition of the tested phospholipid products and a sometimes inadequate poor description of their composition in specific publications, which makes a systematic comparison between published data difficult and the presented data unreliable. In addition, experimental methods for determination of HLB values are mostly short-term tests, which are not indicative of a long-term stability of the emulsions. It should be further realized that natural phospholipids if manufactured/fractionated reproducibly at high standards from, e.g., crude lecithin, do represent well-defined mixtures of phospholipids like PC, PE and PI. These phospholipid mixtures display a reproducible, origin (raw material)-specific, heterogeneous but reproducible fatty acid composition and are considered as well-defined mixtures of co-emulsifiers.

In cosmetic products, phospholipids are often used as co-emulsifier in combination with synthetic (non-natural) emulsifiers. Besides the fact that these products are not natural anymore, phospholipids can, as demonstrated in the following, also be used as sole emulsifiers in natural cosmetic products, eliminating the need for synthetic emulsifiers.

The following emulsification experiments were performed with a model formulation using various phospholipids as the only variable and sole emulsifier. In Table 6.6, the recipe of the model formulation (adjusted to $\mathrm{pH} 5.5$ ) is shown.

A comparison of different emulsifying properties of phospholipids for the preparation of $\mathrm{o} / \mathrm{w}$ emulsions with various oils (differing in required HLB value) is provided in Table 6.7.

The oil-in-water emulsions were prepared by using either MCT (medium-chain triglycerides, with required HLB 4), jojoba oil (with required HLB value 6), sunflower oil (with required HLB value 7) or squalane (with required HLB 11), or as oil phase, mixing components of Phase A (oil and phospholipid) and heating to $70^{\circ}$ $\mathrm{C}$ until a clear solution was obtained. Separately, Phase B (water, glycerine) was heated to $70{ }^{\circ} \mathrm{C}$ and added to Phase A under stirring. In case the phospholipid was

Table 6.6 Recipe of a model formulation to compare the emulsifying properties of phospholipid emulsifiers to prepare oil-in-water emulsions

\begin{tabular}{l|l|l|l}
\hline Phase & INCI & Function & $\%(\mathrm{w} / \mathrm{w})$ \\
\hline A & Oil & Lipophilic phase & 25.00 \\
\cline { 2 - 4 } & Phospholipid $^{\mathrm{a}}$ & Emulsifier & 3.00 \\
\hline $\mathrm{B}$ & Aqua/water & Hydrophilic phase & 64.00 \\
\cline { 2 - 4 } & Glycerine & Moisturizer & 6.00 \\
\hline C & Xanthan gum & Thickener & 0.20 \\
\cline { 2 - 4 } & Dehydroxanthan gum & Thickener & 0.80 \\
\hline D & $\begin{array}{l}\text { Benzyl alcohol, glycerine, benzoic acid, } \\
\text { sorbic acid (Rokonsal }\end{array}$ BSB-N) & $\begin{array}{l}\text { Antimicrobial } \\
\text { preservative }\end{array}$ & 1.00 \\
\cline { 2 - 4 } & Sodium hydroxide & pH adjustment & q.s. \\
\cline { 2 - 4 } & Citric acid & pH adjustment & q.s. \\
\hline Total & & & 100.00 \\
\hline
\end{tabular}

${ }^{\mathrm{a}}$ Tested phospholipids are described in Table 6.7 
Table 6.7 Influence of soybean phospholipids and oil phase HLB on the stability of model oil-in-water emulsions

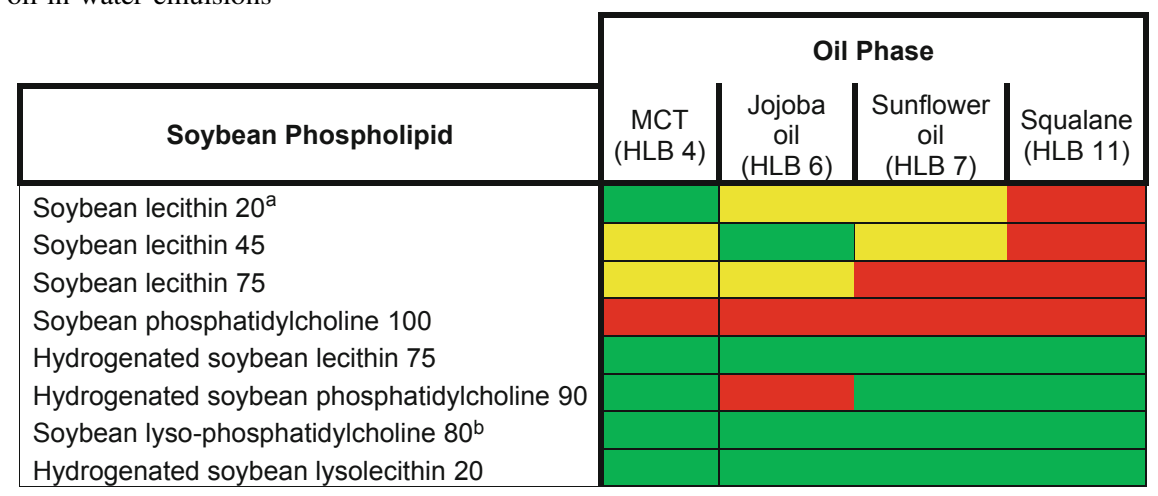

Green: stable for at least six weeks at $45{ }^{\circ} \mathrm{C}$ and five freeze-thaw cycles; Yellow: maximal stability three weeks at $45{ }^{\circ} \mathrm{C}$, Red: no emulsion was formed (for further details see text). The numbers refer to the ${ }^{\mathrm{a}} \mathrm{PC}$ content or ${ }^{\mathrm{b}}$ lyso-PC content; data kindly provided by Lipoid GmbH, Ludwigshafen am Rhein, Germany)

not soluble in the oil phase at this temperature (e.g. hydrogenated phosphatidylcholine with $>90 \%$ PC), it was dispersed in Phase B (water, glycerine), and Phase A was added to Phase B; then both phases were intensively emulsified using a rotor-stator mixer $(5 \mathrm{~min})$. Under stirring, the thickeners were added in portions to the emulsion and cooled down to $30{ }^{\circ} \mathrm{C}$. Finally, the emulsion was homogenised again with a rotor-stator mixer for $1 \mathrm{~min}$, the antimicrobial preservatives were added, and the $\mathrm{pH}$ was adjusted to $\mathrm{pH} 5.5$ under stirring.

The stability of the resulting emulsions was tested after one, three and six weeks at $45{ }^{\circ} \mathrm{C}$ and subsequently in five freeze-thaw cycles and inspected for phase separation. The results are provided in Table 6.7.

From this table, it can be concluded that under the test conditions used, unsaturated diacyllecithins are less suitable as sole emulsifiers for oil-in-water emulsions compared to saturated and monoacyl-lipids. The poor results obtained with the pure PC fraction are probably due to the lack of stabilizing components like PE. It should be noted that these phospholipid fractions can still be suitable emulsifiers in other settings (e.g. combined with co-emulsifiers and using high-pressure homogenization).

Hydrogenated soybean phospholipids with 75 or $90 \%$ PC are suitable as sole emulsifiers for oils requiring HLB values form 4-11. The slightly better performance of the hydrogenated soybean phospholipids with $75 \%$ PC is interesting, as this intermediate grade lecithin may present an ideal mixture of phospholipid co-emulsifiers differing in the polar head group. In addition, this lipid provides a pleasant, non-greasy skin feel. It goes without saying that the phospholipids can also be used as co-emulsifiers.

As to be expected, the monoacylphospholipid products are (under the used test conditions) also excellent sole emulsifiers for oil-in-water emulsions over a broad 
range of HLB values. This result is not surprising since it is known that monoacylphospholipids due to their large polar head group surface area (phosphocholine) and the small area cross section of the fatty acid form a cone-like structure, fitting perfectly to the curvature of the oil-water interface in oil-in-water emulsions [41].

In general, Table 6.7 shows that the various phospholipid products differ enormously in emulsifying properties. It should be further realized that these findings are related to the chosen used test formulation. Other additional formulation components may convert a poor oil-in-water emulsion into an acceptable cosmetic formulation. For the design of oil-in-water emulsions, it is recommended to first start to explore a hydrogenated phospholipid fraction containing about 60 $70 \%$ PC and not less than 10\% PE as an emulsifier.

In summary, it has been shown that hydrogenated diacylphospholipids and (un) saturated monoacylphospholipids are excellent emulsifiers for oil-in-water emulsions. The hydrogenated phospholipids have the advantage that they give rise to a pleasant skin feel, whereas the use of monoacylphospholipids makes the manufacturing of such emulsions easier.

A similar approach was used to test the capability of phospholipids as sole emulsifiers for the preparation of water-in-oil emulsions. Pure soybean PC was not an adequate emulsifier for preparation of water-in-oil emulsions, whereas soybean fractions lower in PC and higher in PE yielded water-in-oil emulsions. Hydrogenated (i.e. fully saturated) PC and PC/PE fractions yielded oil-in-water emulsions. In the range of pure $\mathrm{PE}$, phospholipids, e.g. unsaturated soybean PE with 98\% PE, worked as an excellent emulsifier for water-in-oil emulsions, whereas the use of saturated compounds did not result in stable emulsions. This is in agreement with the geometry of the PE molecule which suites perfectly to the curvature of the oil-water interface in water-in-oil emulsions [41].

In summary, phospholipids, representing a broad range of chemical structures and polarities, show in general a very high emulsifying power for different oil phases and can be used as sole emulsifiers. Hydrogenated diacylphospholipids and (un)saturated monoacylphospholipids are very suitable to prepare oil-in-water emulsions for a broad range of oils. The diacylphospholipids are preferred since they are skin protective and have a pleasant non-greasy skin feel. Unsaturated phospholipid fractions lower in PC and higher in PE (which has a small polar head group and a larger lipophilic part) are suitable for preparation of water-in-oil emulsions with certain oil phases, whereas phospholipids with a large polar head group and a smaller lipophilic part, like lyso-phospholipids, are suitable for oil-in-water emulsions [42].

\subsubsection{Liposome/Lamellar Phase Former}

A unique feature of phospholipids compared to other emulsifiers is that they are able to form, upon hydration, closed vesicular structures called liposomes comprising a bilayer of phospholipids surrounding an aqueous vacuole. Although such vesicles can also be made with synthetic compounds like non-ionic surfactants of the alkyl or dialkyl polyglycerol ether class and cholesterol (Niosomes) [43], 
liposomes comprising phospholipids of natural origin are clearly preferred in natural cosmetic products.

Liposomes are intriguing because of their similarity with the basic structure of a natural cell membrane being a bilayer of phospholipid molecules which serves as a matrix for membrane proteins. This natural role makes clear that this structure must be biocompatible and also biodegradable. For use in cosmetic formulations, the following features are of importance:

The size and composition of the liposomes (as discussed above) may influence the degree of skin interaction (or kinetics of disintegration upon passage into the skin and distribution of phospholipids in the skin layers reached by the liposomes), without increasing the risk that the liposomes and their encapsulated content can become systemically bioavailable.

Several types of liposomes exist: small unilamellar vesicles (SUVs) with a particle size $<100 \mathrm{~nm}$, large unilamellar vesicles (LUVs) with a particle size 100 $500 \mathrm{~nm}$ and multilamellar vesicles (MLVs) with particle size $500 \mathrm{~nm}$ to several microns. For cosmetic use, LUVs are most common, because the degree of encapsulation of water-soluble compounds is influenced by the morphology of the liposomes and size [44]. Large unilamellar vesicles have an encapsulated aqueous volume large enough to encapsulate water-soluble compounds efficiently. The size of these liposomes is also in the range enabling a good skin interaction (compare with properties of formulation like the Natipide ${ }^{\circledR}$ product, below) and they can be manufactured easily, especially when using the concept described below.

The lamellarity of liposomes, i.e. the number of membranes (bilayers) per liposomes, in the form of multilamellar liposomes is of limited importance because of the larger particle size which is not favourable for obtaining an adequate skin penetration. Lamellarity in the form of extensive lamellae which comprise saturated phospholipids is, however, of great importance. Extensive lamellae represent a skin like a barrier able to provide an excellent skin protective effect (an example of such a lamellar cream product is "Skin Lipid Matrix $\left.{ }^{\circledR} "\right)$.

The so-called phase transition temperature at which the fatty acids of the phospholipid molecules change (upon cooling) from a mobile state (liquid crystalline) to a rigid state (gel state) is very important for the use of phospholipid in cosmetic formulations. Below this temperature, phospholipids and liposomes have a more rigid character and do not tend to penetrate significantly into the skin but act more as a protective, skin compatible layer. Saturated phospholipids, which have a phase transition temperature around $40-60{ }^{\circ} \mathrm{C}$, have such a rigid structure at the skin temperature of $32{ }^{\circ} \mathrm{C}$. Unsaturated phospholipids have a phase transition temperature below $0{ }^{\circ} \mathrm{C}$ and are at skin temperature in the mobile state. The resulting liposomes comprising these lipids possess at skin temperature a flexible character, and they are able to penetrate deeper into the skin compared to rigid liposomes.

The lipid composition of the liposomes is therefore of interest to manipulate the cosmetic use with respect to a deeper skin penetration or application of liposomes as a skin protectant. At wish, the composition and flexibility of liposomes can be manipulated by adding, e.g., either other detergents [e.g. monoacylphospholipid 
(lysolecithin)] to the liposomes to make them more flexible, or to add saturated phospholipids to make them more rigid. The liposomes are of course, in addition, a source of phospholipids which may be considered as cosmetic actives (see below). In general, liposomes are, since the introduction of liposomes on the cosmetic market (CAPTURE $^{\circledR}$ of Dior), regarded as the classical standard for an anti-ageing product.

\subsubsection{Solubilizer}

Phospholipids play a role in various cosmetic formulations as solubilizers. They are used as an emulsifier in an oil-in-water emulsion with an oil-droplet size of about $50 \mathrm{~nm}$ as part of micro-emulsions (an example of such product is PhytoSolve ${ }^{\circledR}$ ). The oil phase may be an oil of cosmetic interest or/and serves as solubilizing phase, together with the phospholipid at the oil-water interface, to dissolve other (oil-soluble) lipophilic components of, e.g., plant extracts. Furthermore, phospholipids can be used in mixed micelles comprising mono- and diacylphospholipid or diacylphospholipids in combination with another detergent to solubilize lipophilic compounds. Also, liposomes have the possibility to solubilize compounds in the lipophilic part of the liposomal bilayer membrane. There are types of products available which are clear phospholipid concentrates in oily excipients that can be used as a solubilizing vehicle.

\subsubsection{Wetting Agent}

Due to their amphiphilic properties, phospholipids are excellent wetting agents to disperse lipophilic compounds, like color pigments in hydrophilic media [45, 46].

\subsubsection{Actives}

Phospholipids contribute to the efficacy of skin and hair care products. They form very thin mono- or oligolamellar layers on the skin which remain even after washing and have the following positive effects:

- better smoothness and suppleness of the skin

- protection against degreasing

- improved moisture balance of the skin

- improved combing quality and reduced electrostatic charge of the hair.

Saturated as well as unsaturated phospholipids can be used as actives. Referring to their multifunctionality, they can be used as surface-active agent as well as for skin transport enhancement of co-formulated compounds of cosmetic interest.

\subsubsection{Moisturizer}

As mentioned before, phospholipids possess hygroscopic properties and are able to bind water molecules. As a result, phospholipids which are able to penetrate into the skin act as a moisturizer and increase the degree of hydration of the skin. In addition, phospholipids act as a moisturizer as result of metabolism of the 
phospholipids in the skin. In the skin, PC is metabolized by phospholipase A (PLA) and phospholipase D (PLD) enzymes into choline, betaine and glycerophosphocholine (GPC), respectively. These metabolites are called osmoprotectants, also known as osmolytes and/or (most precisely) counteracting osmolytes, able to attract water molecules. These osmolytes are not able to penetrate into membranes and are able to generate an osmotic gradient over the cell membrane. These considerations explain the water binding and attracting properties and there resulting skin moisturizing effect of phospholipids.

The influence of the soybean PC concentration on skin humidity was studied after a single application to the skin of formulations containing $0 \%$ (control with $0.9 \% \mathrm{NaCl}$ ), or a $10 \%(\mathrm{w} / \mathrm{w})$ liposomal dispersion containing phospholipids with varying PC content $(10,28$ and $80 \%$, respectively) to ten volunteers [47].

The obtained results (Fig. 6.11) show an acute and significant increase of the skin humidity for the formulation with a $10 \%(\mathrm{w} / \mathrm{w})$ liposome dispersion containing phospholipids with $80 \%$ soybean PC. The formulation containing $10 \%(\mathrm{w} / \mathrm{w})$ liposome dispersion with phospholipids containing 28\% soybean PC showed a weaker effect. In comparison, the formulation with $10 \%$ (w/w) liposome dispersion with phospholipids containing $10 \%$ soybean PC demonstrated a reduction of the skin humidity. Since the only difference between these formulations is the content of soybean PC, the conclusion can be drawn that PC provides a moisturizing effect to the stratum corneum. This conclusion was underscored by a second multiple application study, which demonstrated an increase of skin humidity to steady-state levels.

\subsubsection{Effect on Skin Roughness}

The influence of the presence of soybean PC in topical formulations on the skin roughness was studied by comparing an aqueous soybean PC containing liposome

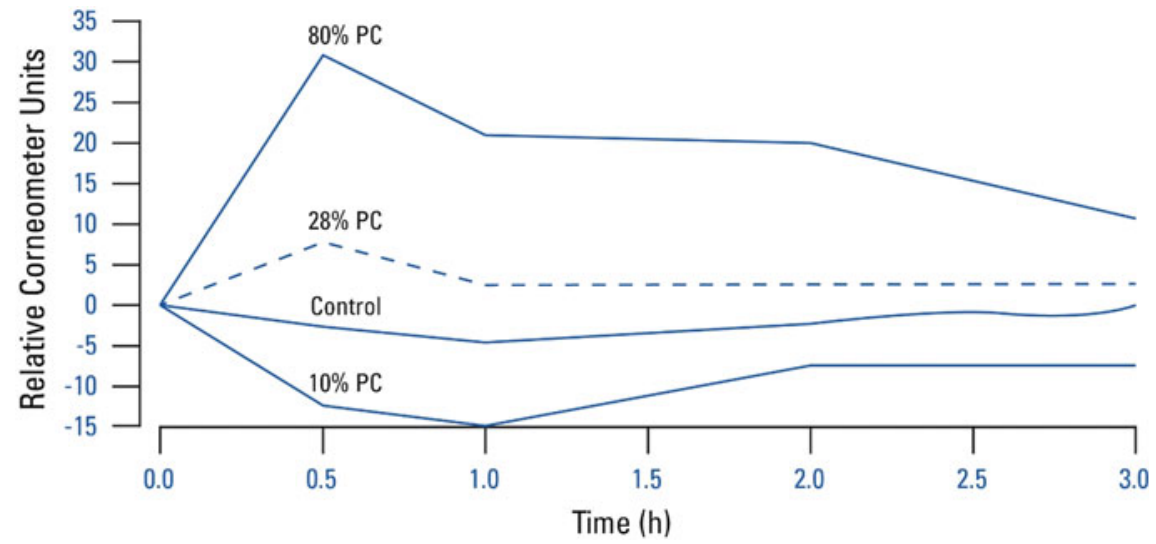

Fig. 6.11 Influence of soybean PC content in topical formulations on the degree of humidity of the human skin after a single application to ten healthy volunteers [48] 


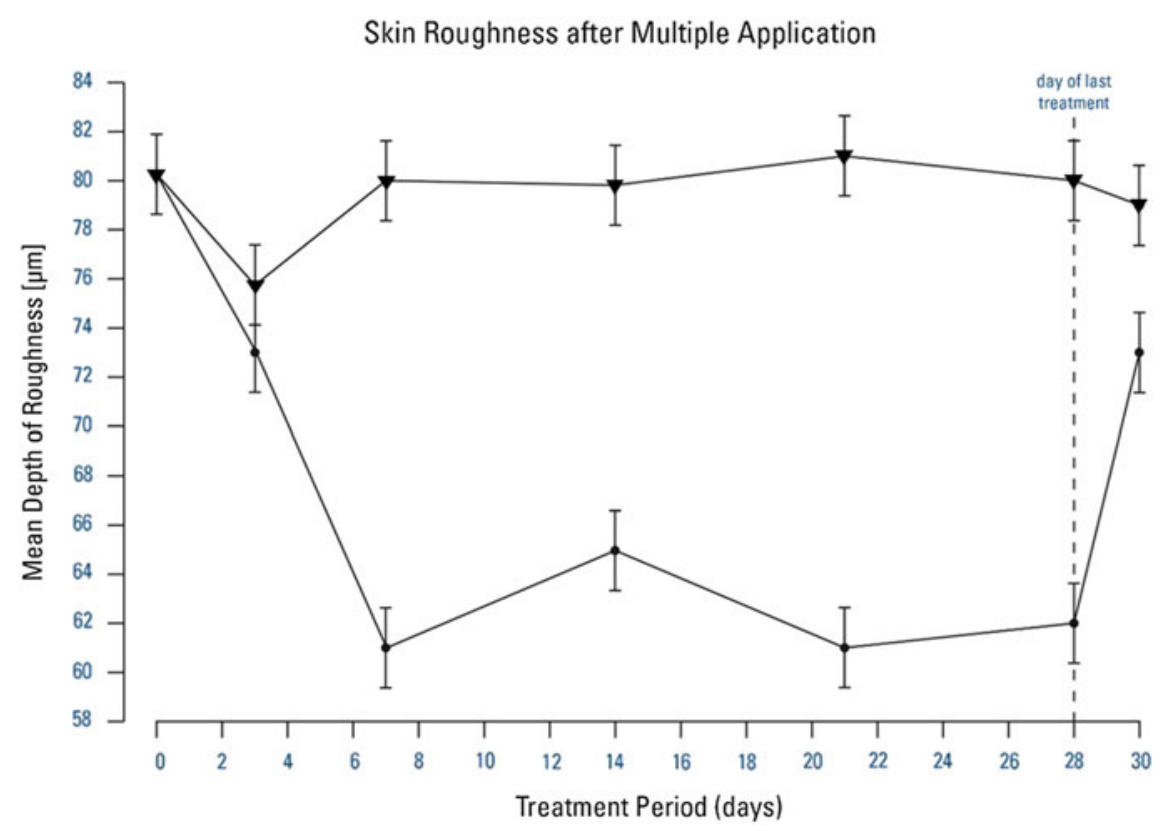

Fig. 6.12 Effect of a formulation with 20.6\% soybean PC on the roughness of the human skin after repetitive application to healthy volunteers $(n=20)$. - Soybean PC containing formulation; $\boldsymbol{\nabla}-\boldsymbol{\nabla}$ o/w emulsion [48]

dispersion with $20.6 \%$ w/v soybean PC (with $93 \%$ PC) and ca. $16 \%$ ethanol with an oil-in-water emulsion after repetitive applications to 20 volunteers (Fig. 6.12) [48].

It was found that the skin roughness was significantly decreased in the group treated with formulation containing soybean PC.

\subsubsection{Effect on Skin Barrier}

Topical formulations comprising of saturated soybean PC possess a skin protective function. They restore and stabilize the skin barrier layers. Measurement of the transepidermal water loss (TEWL) showed that formulations with hydrogenated (saturated) soybean PC restore the natural TEWL level of irritated dry skin. Formulations with HSPC comprise lamellar structures, which are layered on top of each other very similar to the skin structures [49].

Beneficial effects by hydrogenated (saturated) soybean PC were demonstrated in a study [9] involving volunteers subjected to repeated arm washings with the skin irritant sodium lauryl sulphate (SLS). SLS challenge of human skin is generally recognized as the most convincing method for imitating dry skin conditions. The results demonstrated significant improvements in erythema associated with challenged skin samples treated with $1 \%$ aqueous hydrogenated (saturated) soybean PC dispersion samples following the washings compared to those without hydrogenated (saturated) soybean PC as determined by a chromameter. The results also 
showed significant increases in skin moisture contents for the hydrogenated (saturated) soybean PC dispersion. In a separate study involving the healthy skin, addition of 2 and $4 \%$ hydrogenated (saturated) soybean PC to conventional cream bases provided superior long-acting hydration activity and smoothness features to the skin of healthy female volunteers when compared to similar conventional creams without hydrogenated (saturated) soybean PC. The study involved twice-daily cream applications during a 28-day time period and corneometer readings taken at 28, 29 and 31 days. Both HSPC formulations displayed similar efficacy with optimal beneficial effect apparently achieved at the $2 \%$ level.

These beneficial effects of saturated soybean PC are also explained by the presence of large lamellae in the formulations which mimic skin layers (see Fig. 6.13) able to integrate seamlessly in the skin barrier to stimulate skin regeneration [50].

Finally, the use of hydrogenated (saturated) soybean PC results in products with a pleasant, very soft skin feel. For these reasons, this formulation principle is applied in dermatocosmetic products like Physiogel ${ }^{\circledR}$ AI for skin care of neurodermatitis patients. An example of a cosmetic lamellar cream base suitable to prepare such products is described below (Skin Lipid Matrix ${ }^{\circledR}$ ).

\subsubsection{Biochemical Actives}

The positive impacts of phosphatidylcholine from soybean in the treatment of acne vulgaris, atopic dermatitis and other inflammations of the skin are described in numerous papers. Upon application to the skin, unsaturated diacylphospholipids like soybean PC act as a source of linoleic and linolenic acid (Table 6.1). The fraction of administered phospholipids containing linoleic acid reaching metabolic active skin cells may also strengthen the natural barrier function of the skin through

Fig. 6.13 Electron microscopic freeze-fracture picture of SLM 2026 a lamellar cream base comprising saturated phospholipids arranged in lamellar structures (photograph kindly provided by Lipoid $\mathrm{GmbH}$ )

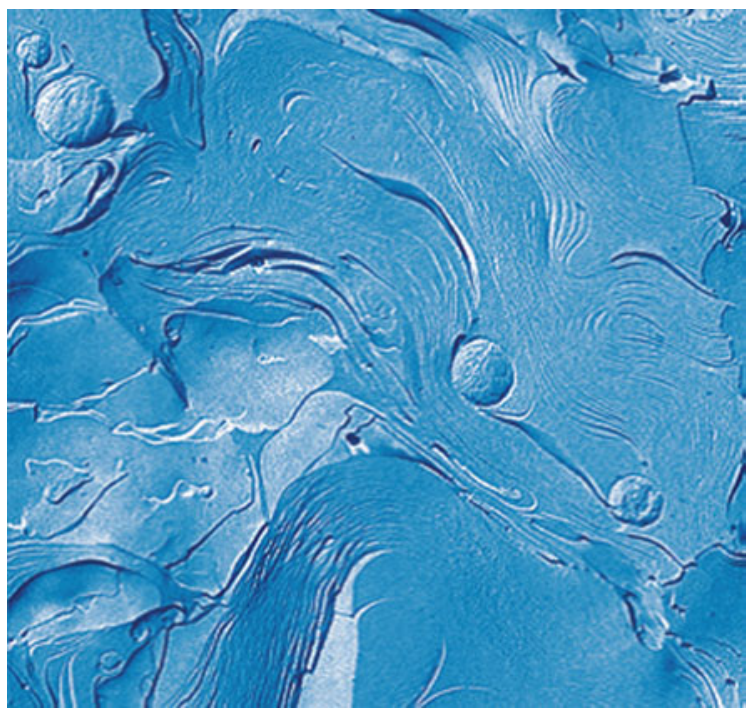


incorporation into skin ceramides. In addition, these phospholipids may play a role in the suppression of acne [51-53], neurodermatitis and psoriasis [49, 54]. The linolenic acid bound to phosphatidylcholine can be eventually converted to a certain extent to omega-3 fatty acids docosahexaenoic acid (DHA, 22:6n-3) and eicosapentaenoic acid (EPA, 20:5n-3).

In an in vitro cell study (data kindly provided by Lipoid $\mathrm{GmbH}$, Ludwigshafen am Rhein, Germany), the effects of soybean phosphatidylcholine with $90 \%$ PC on the in vitro release of pro-MMP1 (MMP = matrix metalloprotease), on MMP1 activity and on the secretion of hyaluronic acid (HA) by Normal Human Dermal Fibroblasts (NHDF) fibroblasts, were investigated.

The analysis of the effects of PC ( $>90 \%)$ from soybean on the production of HA (hyaluronic acid) and on the production and activity of MMP1 (matrix metalloprotease-1) was performed on NHDF fibroblasts seeded in 24-well plates $24 \mathrm{~h}$ before the application of the phospholipid formulation and the reference molecules. The phospholipid was dispersed in $0.9 \% \mathrm{NaCl}$ and applied during $72 \mathrm{~h}$ in the culture medium of NHDFs in serum-free DMEM medium. The reference molecules LPA (1-oleoyl-L- $\alpha$-lysophosphatidic acid sodium salt) at $3 \mu \mathrm{M}$ as control for HA release, TGF- $\beta 1$ (tissue growth factor) at $20 \mathrm{ng} / \mathrm{ml}$ as control for MMP1 release and PMA (phorbol myristate acetate) at $60 \mathrm{ng} / \mathrm{ml}$ as control for MMP1 activity were applied in parallel (Table 6.8). The concentrations of released, HA, Pro-MMP1 and MMP1 were determined by compound-specific assay kits.

The PC product increased the release of extracellular hyaluronic acid and decreased MMP1 activity within cultured NHDFs fibroblasts. This underscores that soybean phosphatidylcholine with $90 \%$ PC has a moisturizing effect and a potential to increase the firmness of the dermis, which is associated with better maintenance of the collagen resulting in an anti-ageing effect.

Table 6.8 Quantification of HA release and pro-MMP1 release and MMP1 activity from NHDFs fibroblasts; for explanation of abbreviations, see text

\begin{tabular}{l|l|l|l|l}
\hline Treatments & Concentrations & $\begin{array}{l}\text { HA } \\
\text { release }\end{array}$ & $\begin{array}{l}\text { Pro-MMP1 } \\
\text { release }\end{array}$ & $\begin{array}{l}\text { MMP1 } \\
\text { activity }\end{array}$ \\
\hline $\begin{array}{l}\text { LPA (compared to untreated } \\
\text { control) }\end{array}$ & $3 \mu \mathrm{M}$ & $\nearrow \nearrow \nearrow$ & - & - \\
\hline $\begin{array}{l}\text { TGF- } \beta 1 \text { (compared to untreated } \\
\text { control) }\end{array}$ & $20 \mathrm{ng} / \mathrm{ml}$ & - & $\nearrow \nearrow$ & - \\
\hline $\begin{array}{l}\text { PMA (compared to untreated } \\
\text { control) }\end{array}$ & $60 \mathrm{ng} / \mathrm{ml}$ & - & - & $\nearrow \nearrow$ \\
\hline $\begin{array}{l}\text { Soybean phosphatidylcholine } 90 \\
\text { compared to vehicle } 0.9 \% \mathrm{NaCl} \text { ) }\end{array}$ & $0.0016 \%$ & $\nearrow \nearrow$ & $\mathrm{NS}$ & $\searrow$ \\
\hline
\end{tabular}

The statistical significance of the data, as compared to control conditions, is presented by $\searrow$ (decrease) and $\nearrow$ (increase), highly significant differences are represented by $\nearrow \nearrow$ (increase) and $\searrow \searrow$ (decrease), and very highly significant differences are represented by $\nearrow \nearrow \nearrow$ (increase) and $\searrow \searrow \searrow$ (decrease). NS - non-significant effects (data kindly provided by Lipoid GmbH) 
In a further in vitro cell test on normal human epidermal keratinocytes (NHEKs), which were in a chemical induced inflammatory state, it could be proven that soybean phosphatidylcholine with $90 \%$ PC could suppress the secretion of TNF- $\alpha$ suggesting an anti-inflammatory potential (detailed data not shown).

Also, other phospholipids beside phosphatidylcholine may have specific benefits to be used in cosmetic formulations. For instance, it is claimed that phosphatidic acid stimulates hair growth [55].

In a patent application [56], it is claimed that phosphatidylinositol acts as vascular endothelial cell proliferation inhibitor and/or vascularization inhibitor. It is further claimed that PI could be advantageous as for cosmetic use by suppressing skin inflammation and related skin irritation.

Phosphatidylserine stimulates differentiation of keratinocytes which gives rise to an enhancement of the skin barrier [57].

\subsubsection{Transport/Penetration Enhancement}

The co-administration of cosmetic actives with phospholipids will influence the degree of skin interaction of these actives. Phospholipids represent a marvellous toolbox to design and predetermine a skin interaction profile of the formulated active. This profile can be influenced by the type of phospholipid used (saturated or unsaturated), type of formulation and particle size of the formulation. Also the selection of the type of formulation should be related to the solubility characteristics of the actives.

In order to stimulate transport/skin penetration of actives into the skin, liposomes or other formulations like oil-in-water emulsions comprising flexible unsaturated phospholipids are the first choice. It is assumed that the barrier properties of the membranes of the stratum corneum, which contain ceramides, are modified after incorporation of the flexible soybean PC molecules. The fluidity of the lipid barrier is thereby increased. The depth of modification is strongly dependent on the concentration of PC and which PC species is being used.

The skin penetration effect of unsaturated phospholipids (particularly soybean PC) has been the topic of several studies.

Verma et al. [58] showed that the very hydrophilic molecule carboxyfluorescein entrapped in flexible liposomes, comprising soybean phosphatidylcholine, penetrates through the stratum corneum into the viable epidermis to a small, but significant extent. Carboxyfluorescein only added outside of the liposomal suspension showed less permeation. A buffer solution of carboxyfluorescein failed to show any fluorescence in the viable epidermis.

In addition, it was shown that the depth of penetration of carboxyfluorescein-loaded liposomes was determined by the particle size [59]. Flexible liposomes with sizes of ca. $120 \mathrm{~nm}$ showed enhanced penetration of carboxyfluorescein (hydrophilic model drug) and of DiI (i.e. 1,1'dioctadecyl-3,3,3',3'-tetramethylindocarbocyanine perchlorate, a lipophilic model drug) into the stratum corneum and epidermis. The penetration depth of the model 
drugs decreased gradually with larger liposomes; $810 \mathrm{~nm}$ sized liposomes could only to a smaller extent deliver the carboxyfluorescein restricted to the outer layers of the stratum corneum, whereas DiI due to its small size and lipophilic character permeates on its own to a slightly larger extent into the epidermis.

Lipophilic compounds may be associated with the liposomal bilayer, where the fatty acids, which are directed to each other, represent a solubilization domain in the membrane. In this way the liposome can carry and co-migrate a lipophilic compound [60].

In case of the lipophilic compound caffeine, it was shown that soybean lecithin liposomes enhanced the skin penetration of caffeine compared to the control formulation without phospholipids. It was further found that the better penetration of caffeine was caused by the presence of the phospholipids in the formulation and not necessarily by the encapsulation in liposomes [61].

Röding et al. [62, 63] assessed the degree of skin penetration of soybean phosphatidylcholine liposomes, ${ }^{3} \mathrm{H}$-labelled (in fatty acid) liposomes after application to porcine skin non-occlusively at $1 \mathrm{mg}$ phospholipid/ $\mathrm{cm}^{2}$ skin. After 30,60 and $180 \mathrm{~min}$, the phospholipid concentration in the stratum corneum and underlying skin layers was determined using liquid scintillation counting on samples obtained by 20 -fold stripping and subsequent tissue sampling. The results provided in Table 6.9 show that more than $99 \%$ of the applied PC accumulates in the stratum corneum, suggesting that the liposomes strongly interact with the stratum corneum lipids.

The fluidization properties of the lipid matrix and resulting enhanced penetration of UV absorber bis-ethylhexyloxyphenol methoxyphenyl triazine caused by liposomal phospholipids may also explain the water resistance of skin treated with liposomal sunscreen formulations, maintaining the protective effect of the UV absorber [64]. In contrast to non-liposomal formulations, the liposomal formulation was more effective after water sweeping tests. Obviously, the sun protective effect is not diminished after contact with water, which is most probably caused by the better penetration of the UV absorber into the upper layers of the stratum corneum as result of the interaction with the skin.

Table 6.9 Penetration of ${ }^{3} \mathrm{H}$-labelled liposomes into porcine skin three hours after single application at $1 \mathrm{mg}$ phospholipid $/ \mathrm{cm}^{2}$ skin $[62,63]$

\begin{tabular}{l|l|l}
\hline Skin strips/cuts & Skin section & $\mu \mathrm{g}$ liposomal phospholipid/g tissue \\
\hline $20 \mathrm{strips}$ & Stratum corneum & 100,000 \\
\hline $1 \mathrm{~mm}$ & Epidermis & 500 \\
\hline $2 \mathrm{~mm}$ & Dermis & 20 \\
\hline $3 \mathrm{~mm}$ & Subcutis & 8 \\
\hline $4 \mathrm{~mm}$ & Subcutaneous fat & 8 \\
\hline $5 \mathrm{~mm}$ & Subcutaneous fat & 12
\end{tabular}


Also in case of $\mathrm{TiO}_{2}$ sunscreen particles, beneficial skin penetration effects could be observed when using liposomes composed of soybean phosphatidylcholine compared to a mixed micellar formulation [65].

The skin whitening effect of linoleic acid could also be enhanced by the use of soybean phosphatidylcholine liposomes compared to a hydrogel formulations [66].

Corderch et al. [67] studied the percutaneous absorption of sodium fluorescein $(\mathrm{NaFl})$ vehiculized in two different liposomes using either phosphatidylcholine or lipids mimicking the stratum corneum (ceramides, cholesterol, palmitic acid and cholesteryl sulphate), respectively. The effect of these vesicles on the stratum corneum lipid alkyl chain conformational order was evaluated at different depths of the stratum corneum by corneometer, tewameter and ATR-FTIR. The highest penetration of $\mathrm{NaFl}$ was observed with $\mathrm{PC}$ liposomes, which could be related to the increase in stratum corneum lipid disorder detected by ATR-FTIR.

The penetration of liposomes with encapsulated fluorescent dye carboxyfluorescein into the human abdomen skin studied by fluorescence microscopy showed that liposomes made from fluid-state PC (di-lauroyl-PC) compared to liposomes composed of gel state (rigid) DSPC (di-stearoyl-PC) are taken up by the skin more readily, permeate faster and penetrate beyond the stratum corneum [68]. These findings suggest that rigid saturated phospholipids, and most probably also the accompanying water, are taken up by the stratum corneum but not by the deeper layers of the skin. In addition, saturated phospholipids seem to perturb the lipid barrier to a lesser extent as unsaturated soybean phospholipids.

The differences of skin penetration pattern between liposomes comprising either unsaturated or saturated phospholipids were also studied with liposomes simultaneously labelled with the hydrophilic water-soluble fluorescent marker carboxyfluorescein and a lipophilic fluorescent marker N-rhodamine PE [69] employing confocal laser microscopy. Indeed, it was found that the liposomes comprising saturated phospholipids were more located at the surface of the stratum corneum, whereas liposome comprising unsaturated phospholipid resulted in a localization of both markers in deeper layers of the studied skin fragments underscoring their suitability as penetration enhancer (see Discussion section for photographs).

Perez-Cullell et al. demonstrated that the skin penetration of sodium fluorescein was higher from fluid liposomes (PC) than from rigid liposomes (hydrogenated phosphatidylcholine). They conclude that the liquid crystalline phospholipids interact with the lipids of the stratum corneum by means of disintegration of the vesicles during their passage through the lipid intercellular pathway in the stratum corneum [70].

Yokomizo and Sagitani [71] observed with ATN-FTIR that liposomes, loaded with prednisolone, comprising phospholipids that have unsaturated acyl chains induced higher and broader absorbance shifts in the $\mathrm{C}-\mathrm{H}$ bond-stretching region of the stratum corneum while phospholipids that have saturated acyl chains induced lower and sharper absorbance shifts in the $\mathrm{C}-\mathrm{H}$ bond-stretching region. A significant parallel between the amount of prednisolone penetrated and the lipid-chain fluidity of the stratum corneum was found. These results suggest that phospholipids 
may influence the percutaneous penetration of prednisolone by changing the lipid-chain fluidity of the stratum corneum.

Komatsu et al. examined the in vivo percutaneous penetration of butylparaben and the saturated dipalmitoylphosphatidylcholine (DPPC) from liposomal suspensions in guinea pigs by autoradiography. They reported that butylparaben penetrated through the skin, whereas DPPC was scarcely detected in the body, suggesting that the liposomes themselves remained on the skin surface [72].

The observation that skin penetration is more enhanced by formulations comprising unsaturated fatty acid containing phospholipids, compared to formulations comprising saturated fatty acid containing phospholipids is supported by the findings of Ibrahim and $\mathrm{Li}$ [73] who showed that also the skin penetration effects of unsaturated versus saturated fatty acids are equally dependent on their melting point.

A typical example of a product, comprising unsaturated soybean phospholipids, used to enhance the skin penetration of water-soluble compounds is described below in more detail.

As the pilosebaceous units (hair follicles) are a kind of extension of epidermis and dermis to the surface of the skin, several studies investigated the targeting of the hair follicles by phospholipid particles. Du Plessis et al. reported that the amount of liposomally entrapped IFN ( $\gamma$-interferon) in the deeper skin strata were in the order of increasing number of follicles/hair in the skin species, suggesting that the transfollicular route is an essential pathway for liposomal topical therapeutics [74]. Lieb et al. showed that topical application of the liposomal-based formulation resulted in a significantly higher accumulation of carboxyfluorescein in the pilosebaceous units than the application of any of the other non-liposomal formulations [75]. Niemiec et al. showed significantly enhanced topical delivery of hydrophilic protein alpha-interferon and hydrophobic peptide cyclosporin-A into pilosebaceous units by non-ionic liposomes [76]. Another study of $\mathrm{Li}$ et al. demonstrated [77] that phosphatidylcholine liposomes entrapping either the fluorescent dye calcein or the pigment melanin can deliver these molecules into the hair follicle and hair shafts of mice when applied topically. In a recent study [78], the influence of massage and occlusion on the follicular penetration depths of rigid and flexible liposomes loaded with a hydrophilic and lipophilic dye was investigated. The application of massage increased follicular penetration significantly. Occlusion resulted in an increased follicular penetration depth only for rigid liposomes.

Employing the hamster ear skin model in a mechanistic study, liposomes of PC, cholesterol and phosphatidylserine delivered the fluorescent hydrophilic dye, carboxyfluorescein, into the pilosebaceous units. They were more efficient than aqueous solutions even after incorporation of $10 \%$ ethanol or $0.05 \%$ sodium lauryl sulphate, or using propylene glycol as the donor vehicle.

Although the particle size and the nano-aspect play an important role for efficient delivery of phospholipids (and associated compounds/actives) to hair follicles to influence the condition of the hair, phospholipids can also be integrated in 
shampoos and hair conditioners, mostly as emulsifier for direct application to the hair [79]. The addition of phospholipids to hair cosmetics may have beneficial effects in conditions like dandruff, hairbrush, hair splitting, lacklustre hair and fat hair.

\subsection{Examples of Phospholipid Formulations}

In the following, typical examples of phospholipid-based products are summarized which highlight the various possibilities to demonstrate the use phospholipids in cosmetic products.

\subsubsection{Lamellae Containing Formulations}

For many years, conventional oil-in-water and water-in-oil emulsions have been the heart of skin care products. However, the classic emulsifiers needed in these products to maintain their stability can also interact with the lipid layers of the stratum corneum. This may cause wash out effects and skin irritations. A big step forward to minimize these disadvantages offers formulations based on lamellar structure (see Fig. 6.13) comprising saturated soybean phosphatidylcholine and which does not contain any classical emulsifier (brand name: Skin Lipid Matrix ${ }^{\circledR}$ (SLM)). The SLM is composed of skin-identical lipids that can regenerate and reconstruct the skin barrier.

The stratum corneum, the horny layer of the epidermis, is composed of two parts, the corneocytes and the lipid matrix which fills the space between them. A disruption of the lipid layer, or the simple lack of skin lipids, can create moisture deficiency and dry skin. The SLM acts as an excellent skin renovator by providing new skin lipids.

There are commercially available products based on this formulation principle with saturated/hydrogenated phosphatidylcholine, also from non-GMO soybean.

\subsubsection{Phospholipid Containing Nano-emulsions}

Highly concentrated solutions of polyols (e.g. glycerol, sorbitol) and phospholipids facilitate the dissolution of a large quantity of lipids and form transparent to translucent nano-emulsions of honey-like to gel-like consistency and with droplet sizes of less than $100 \mathrm{~nm}$. A diverse range of numerous active lipophilic ingredients can be incorporated: vegetable oils, essential oils, mineral oils, vitamins, ceramides or oil-soluble UV filters and pharmaceutically active ingredients.

PhytoSolve $^{\circledR}$ is a brand comprising such a sophisticated solubilization system based on phospholipids. This delivery system with only natural ingredients combines excellent solubilizing function with physiological safeness, being 
well-tolerated by the body and also characterized by ecologically unobjectionable behaviour [80] (Note: NanoSolve ${ }^{\circledR}$ was the original name of this patented technology; this was rebranded to PhytoSolve $\left.{ }^{\circledR}\right)$.

The system works as a versatile medium that accelerates the effects of active ingredients and allows them to penetrate the skin upon dermal application.

The product can be used directly without further processing in cosmetics, topical formulations and may be easily incorporated into any kind of emulsion, gels, sunscreen sprays with oil-soluble UV filters.

\subsubsection{Phospholipid Concentrates}

It has been proven that phosphatidylcholine can improve the solubility and absorption of pharmaceutically active ingredients that are either insoluble or barely soluble in water or only soluble in physiologically unacceptable solvents. In pharmaceutical applications, phosphatidylcholine may reduce objectionable side effects of drug substances and thereby render them physiologically more tolerable. Besides their application in the pharmaceutical oral and parenteral fields, compounds with phosphatidylcholine in mixture with oil featuring higher concentrations of phosphatidylcholine are also suitable for dermal pharmaceutical and cosmetic applications [81]. The designations in the PHOSAL ${ }^{\circledR}$ brand names clearly indicate the medium present in a particular product, e.g. medium-chain triglycerides (MCT), sunflower oil (SB), safflower oil (SA) and propylene glycol (PG). All ingredients of the formulation with phosphatidylcholine are of food-grade quality and provide excellent carriers of natural phosphatidylcholine and lipophilic active ingredients, e.g. vitamins and essential oils. Liquid compounds can directly be incorporated into: emulsions, i.e. creams and lotions.

\subsubsection{Liposomal Concentrates}

A soybean PC-based product for cosmetic use was developed under the brand name Natipide $^{\circledR}[82,83]$. This product, Natipide ${ }^{\circledR}$ II, is a breakthrough for the use of liposomes in cosmetic products because it avoids the need to apply high-pressure homogenizer procedures to make liposomes with sufficiently small size. Instead, this concentrate is a ready-to-use product, which can be used for large-scale production of liposomes by simply diluting the concentrate. It contains a yellowish-brown gel-like liposome concentrate containing a purified phospholipid fraction with high phosphatidylcholine content and ethanol (antimicrobial preservative) and is described as a vesicular gel consisting of densely packed unilamellar liposomes. Recently, a ethanol-free product with non-GMO phospholipids became available (Natipide ${ }^{\circledR}$ Eco).

Electron microscopy shows a gel of closely packed liposomes (Fig. 6.14). These liposomes have leaky membranes because of the presence of ethanol. Upon dilution with an aqueous medium containing a substance of cosmetic interest, the added 
Fig. 6.14 Freeze-fracture electron micrograph of Natipide ${ }^{\circledR}$ II. Bar $=100 \mathrm{~nm}$ (photograph kindly provided by Lipoid $\mathrm{GmbH}$ )

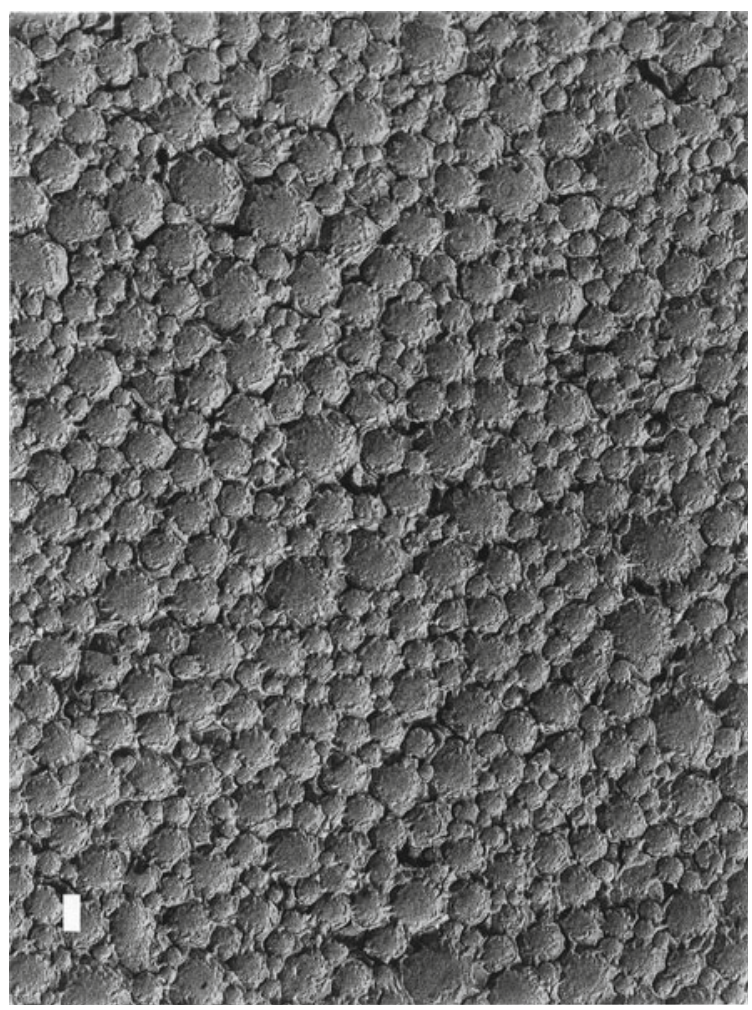

substance equilibrates by means of diffusion over the membrane and is partially encapsulated in the liposomes. This type of formulation represents therefore an ideal skin penetration enhancing vehicle, being a supply of phospholipids which makes the stratum corneum more permeable for the cosmetic actives encapsulated in the liposomes and outside the liposomes.

\subsection{Discussion}

Phospholipids are used in cosmetic formulations, comprising, e.g., emulsions and liposomes. Upon administration to the skin, the liposome or emulsion particles fall gradually apart and release their content and simultaneously distribute the lipid in the surrounding skin layers. This distribution process may be accompanied by a metabolic degradation of the lipids. It is generally accepted that intact liposomes are not able to permeate through the skin at any meaningful level. In spite of these skin distribution properties, the particle size in the nano-range of the lipid particles may determine the depth of penetration. A correlation between particle size and depth of penetration has been found with liposomes but is less clear for (nano)-water-in-oil 
emulsions. It is claimed that a particle size of ca. 100-200 nm is ideal for an optimal skin interaction.

Besides the particle size, the lipid composition/properties of the lipid particles determine to a great extent the degree of interaction with the skin. Diacylphosphatidylcholines are in the liquid crystalline state above the phase transition temperature and below this temperature in the gel state and rigid. Unsaturated phospholipids have a phase transition temperature below $0{ }^{\circ} \mathrm{C}$ and are at $32{ }^{\circ} \mathrm{C}$ in the flexible state. Saturated phospholipids have a transition temperature between ca. 40 and $60{ }^{\circ} \mathrm{C}$ and are in the gel (rigid) state at $32{ }^{\circ} \mathrm{C}$. Lipids which are rigid at the skin temperature of $32{ }^{\circ} \mathrm{C}$ have a lower tendency to penetrate into the stratum corneum compared to lipid particles which comprise lipids which are more flexible at $32{ }^{\circ} \mathrm{C}$.

Soybean PC, i.e. phosphatidylcholines with unsaturated fatty acids, forms flexible liposomes which are able to penetrate more deeply into the skin compared to rigid liposomes/lamellar phases comprising of saturated soybean PC which for these reasons reside predominantly in the upper layers of the skin. Soybean PCs are therefore suitable as penetration enhancers/transportation vehicles to carry co-encapsulated compounds more deeply into the stratum corneum. In addition, they make a contribution to maintain or restore a healthy condition of the skin by means of supply of polyunsaturated fatty acids (linoleic, linolenic and oleic acids). Saturated soybean PCs make another contribution to maintain or restore the healthy condition of the skin by stabilizing the barrier function of the skin in a physical way.

The differences of skin penetration pattern between liposomes comprising either unsaturated or saturated phospholipids were also studied with liposomes simultaneously labelled with a hydrophilic water-soluble fluorescent marker carboxyfluorescein and a lipophilic fluorescent marker N-rhodamine PE [69] and confocal laser microscopy (Fig. 6.15). The photographs impressively show that the liposomes comprising saturated phospholipids were more located at the surface of the stratum corneum, whereas liposome comprising unsaturated phospholipid resulted in a localization of both markers in deeper layers of the studied skin fragments underscoring their suitability as penetration enhancer.

The several ways phospholipid containing lipid particles may interact with the skin and the influence of flexibility/rigidity of the phospholipid molecule are schematically presented (Fig. 6.16).

The penetration depth of the encapsulated compound (or co-administered with the phospholipid formulation) will be substance specific and depends on the physiochemical properties and molecular weight. In Fig. 6.16, the various mechanisms of interaction with the stratum corneum of "free" cosmetic compounds without cosmetic carrier (A) and with cosmetic carrier comprising either saturated (B) or unsaturated phospholipids (C-E) are presented schematically. The carriers could be, e.g., liposomes/lamellar phase or emulsion particles. The compound could be hydrophilic or lipophilic but is in case of a carrier associated with this carrier. 
Skin

(a)

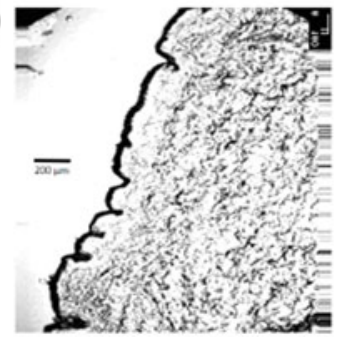

(b)

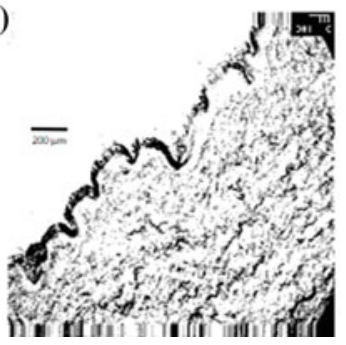

Lipid-detection
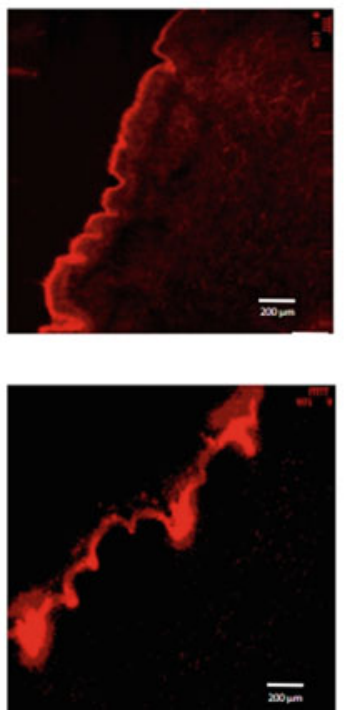

CF-detection
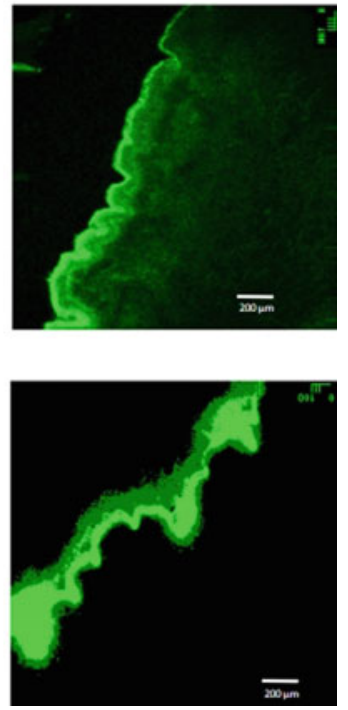

Fig. 6.15 Comparison of skin distribution pattern of liposomes containing the water-soluble marker carboxyfluorescein ( $\mathrm{CF}$ detection) and the lipophilic marker N-rhodamine-PE (lipid detection), comprising either a unsaturated phospholipid or b saturated phospholipids (derived from Fahr et al. [69]). Bar $=200 \mu \mathrm{m}$

In case of the "free" compound, a relatively low degree of penetration into the stratum corneum compared to the scenario with cosmetic carrier can be expected (as depicted with the smaller red arrow) (A).

When the compound is co-administered with a carrier containing rigid, saturated phospholipids, the saturated phospholipid will be embedded in the upper layers of the stratum corneum as lamellar layers, thereby increasing/restoring the barrier function of the stratum corneum (as depicted by the diffuse yellow color of the lipids in the mortar). Depending on the physiochemical properties of the cosmetic compounds, the compound itself may be penetrating deeper and/or slowly released from the lamellae (B).

Co-administration with carriers containing flexible, unsaturated phospholipids results in various interaction possibilities with the stratum corneum. Which mechanism prevails (or the degree of relative contribution of the three discussed mechanisms) regarding penetration will be dependent on the properties of the cosmetic compound and carrier. Anyway, it can be expected, in general, that due to the flexible phospholipids, these phospholipids and the active cosmetic compound are able to penetrate deeper into the stratum corneum compared to the free compound and the scenario with saturated phospholipids (as depicted by the longer red arrow and the diffusion of the orange coloured unsaturated phospholipids and black dots (compounds) (C). Further, (D) represents the interaction option that the carrier 


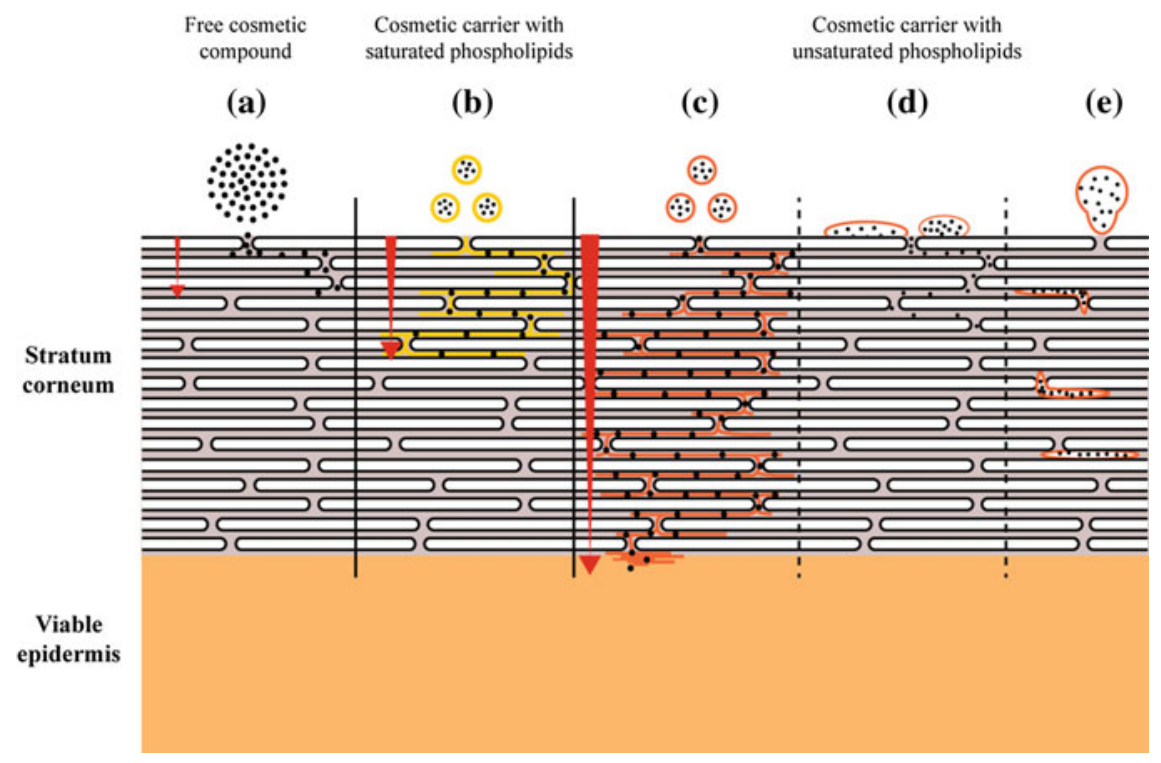

Fig. 6.16 Schematic presentation of the influence of the type of phospholipid (saturated or unsaturated) in emulsion- or liposome-based formulations on the interaction mode of encapsulated cosmetic compounds and used phospholipids with the stratum corneum. a Interaction of free cosmetic compound (black dots) with the stratum corneum, $\mathbf{b}$ interaction of a cosmetic carrier (emulsion particle or liposome) comprising a cosmetic compound (black dots) and saturated phospholipids (yellow color), c penetration enhancing process of cosmetic compound (black dots) by unsaturated phospholipids (orange color), $\mathbf{d}$ adsorption or fusion of cosmetic carrier comprising a cosmetic compound (black dots) and unsaturated phospholipids (orange) with the upper layer of the stratum corneum, e penetration of intact cosmetic carrier, comprising a cosmetic compound (black dots) and unsaturated phospholipid (orange). Red arrows represent the relative depth of penetration into the stratum corneum, of lipid and associated cosmetic compounds

fuses with or adsorbs on the upper layers of the stratum corneum and (E) represents the option that the compounds are co-migrating with intact vesicles (and unsaturated (orange) phospholipids) able to migrate into the stratum corneum.

In Fig. 6.16, the relative penetration depths of cosmetic compounds and phospholipids of the three administration options (free compound/compound with saturated phospholipids/compound with unsaturated phospholipids) are indicated by the lengths of the red arrows. These arrows represent a concentration gradient which ends in the lower layers of the stratum corneum/viable epidermis. As indicated above, the drawing is intended to explain interaction mechanisms and does not present the skin interaction and depth of presentation of any compound. In practice, compounds may penetrate deeper into the skin, especially when they have a low MW and are lipophilic. Also the phospholipids may penetrate deeper than indicated, but as explained above in extenso, to a minor extent. Regarding the skin interaction of unsaturated phospholipids, the degree of contributions of these 
Table 6.10 Relevant characteristics of soybean PC and saturated soybean PC for cosmetic products

\begin{tabular}{|c|c|c|}
\hline Parameter & Soybean PC & Saturated soybean PC \\
\hline $\begin{array}{l}\text { Fatty acid } \\
\text { composition }\end{array}$ & $\begin{array}{l}\text { Unsaturated fatty acids; linoleic, } \\
\text { linolenic and oleic acid }\end{array}$ & $\begin{array}{l}\text { Saturated fatty acids; stearic } \\
\text { and palmitic acid }\end{array}$ \\
\hline $\begin{array}{l}\text { Phase } \\
\text { transition } \\
\text { temperature } \\
\left({ }^{\circ} \mathrm{C}\right)\end{array}$ & Below 0 & $40-60$ \\
\hline $\begin{array}{l}\text { Structure at } \\
\text { skin } \\
\text { temperature }\end{array}$ & Flexible & Rigid \\
\hline $\begin{array}{l}\text { Structures } \\
\text { upon } \\
\text { hydration }\end{array}$ & $\begin{array}{l}\text { Liposomes and lamellar structures } \\
\text { dependent on process conditions }\end{array}$ & $\begin{array}{l}\text { Liposomes and lamellar } \\
\text { structures dependent on process } \\
\text { conditions }\end{array}$ \\
\hline \multicolumn{3}{|c|}{ Surface-active technical ingredient } \\
\hline Emulsifier & Yes, for oil-in-water emulsions & $\begin{array}{l}\text { Yes, for oil-in-water emulsions } \\
\text { More stable than unsaturated } \\
\text { soybean PC; pleasant skin feel, } \\
\text { white/off-white color }\end{array}$ \\
\hline $\begin{array}{l}\text { Dispersing and } \\
\text { solubilizing } \\
\text { ability }\end{array}$ & $\begin{array}{l}\text { Hydrophilic, amphiphilic and lipophilic } \\
\text { compounds }\end{array}$ & $\begin{array}{l}\text { Hydrophilic, amphiphilic and } \\
\text { lipophilic compounds }\end{array}$ \\
\hline $\begin{array}{l}\text { Product } \\
\text { examples }\end{array}$ & - & $\begin{array}{l}\text { Saturated soybean phospholipid } \\
\text { fractions }\end{array}$ \\
\hline \multicolumn{3}{|l|}{ Cosmetic active } \\
\hline $\begin{array}{l}\text { Skin } \\
\text { interaction }\end{array}$ & Not used for restoring skin barrier & $\begin{array}{l}\text { Stabilizing the barrier function; } \\
\text { conditioning the stratum } \\
\text { corneum }\end{array}$ \\
\hline $\begin{array}{l}\text { Barrier } \\
\text { compatibility }\end{array}$ & Yes, slightly enhancing TEWL ${ }^{a}$ & Yes, stabilizing normal TEWL \\
\hline $\begin{array}{l}\text { Supply of } \\
\text { linoleic and } \\
\text { linolenic acid }\end{array}$ & $\begin{array}{l}\text { Yes; beneficial effects of phospholipids } \\
\text { containing omega- } 3 \text { and omega- } 6 \text { fatty } \\
\text { acids on acne vulgaris, psoriasis, } \\
\text { neurodermatitis. Stimulates in vitro } \\
\text { excretion of hyaluronic acid }\end{array}$ & No \\
\hline $\begin{array}{l}\text { Product } \\
\text { example }\end{array}$ & Soybean phosphatidylcholine & Formulations with saturated PC \\
\hline \multicolumn{3}{|l|}{ Transport } \\
\hline $\begin{array}{l}\text { Transport } \\
\text { properties }\end{array}$ & $\begin{array}{l}\text { Penetration enhancement; conditioning } \\
\text { the stratum corneum } \\
\text { Penetrates into the stratum corneum and } \\
\text { into the viable epidermis to a minor } \\
\text { extent }\end{array}$ & $\begin{array}{l}\text { Penetrates only into SC and not } \\
\text { below }\end{array}$ \\
\hline $\begin{array}{l}\text { Product } \\
\text { example }\end{array}$ & $\begin{array}{l}\text { Liposomal formulations with soybean } \\
\text { PC }\end{array}$ & - \\
\hline
\end{tabular}

${ }^{\mathrm{a}} \mathrm{TEWL}$ - transepidermal water loss 
separate interaction modes $(\mathrm{C})-(\mathrm{E})$, to the overall skin interaction is dependent on the cosmetic compound and formulation composition.

Depending on the oil solubility characteristic of the lipophilic actives, also nano-emulsions using rigid saturated or flexible unsaturated phospholipid as emulsifier may be used to carry especially actives with high solubility in the oil phase, or the oil phase as active in the skin.

The properties of unsaturated soybean PC and saturated soybean PC and related cosmetic products and relevant parameters for the design of cosmetic formulations using both classes of phosphatidylcholines are summarized in Table 6.10 (data from $[48,9,84,85])$.

Table 6.10 addresses as well the multifunctional aspects of the use of the main classes of phospholipids (phosphatidylcholines). The table can also be used as guide to select the best possible phospholipid for obtaining a desired property of the cosmetic product

\subsection{Conclusions}

For decades, phospholipids have been used as ingredients in cosmetic products. Before the discovery of liposomes in the late sixties of the past century, the use of phospholipids as emulsifier in cosmetic formulations was prominent. The interest in phospholipids was then greatly enhanced by the introduction of liposomes in the cosmetic industry in 1987. Since then, extensive research, especially in the pharmaceutical area, has been performed on liposomes showing their skin penetration enhancing properties for various compounds. Simultaneously, the attributes of phospholipids as cosmetic and biochemical actives were established. In the last decade, the understanding of the influence of the phase transition temperature on the cosmetic use of phospholipids, either formulated in (mainly) liposomes or emulsions, became apparent.

The above-presented findings make also very clear that phospholipids are not synonymous with liposomes, but are valuable cosmetic ingredients in any other type of formulations as well. Phospholipids have several big advantages in nano-cosmetics. They are natural substances, present in the skin, addressing the cry for using sustainable products and refraining from synthetic compounds in cosmetic industry. By choosing the right components from available natural phospholipid products, they can replace missing or attenuated substances in the stressed skin (e.g. linoleic acid) via intrinsic metabolism pathways in the skin.

Nowadays, phospholipids are considered as unique natural compounds for formulators of cosmetic products. This is owed to their multifunctional properties as a surface-active technical ingredient, cosmetic active and use to enhance the skin interaction/penetration of co-formulated cosmetic actives, in combination with their high degree of skin tolerability. 
Examples of natural phospholipids, which fulfil these properties as:

(1) surface-active ingredients are hydrogenated soybean lecithin with $75 \%$ PC and hydrogenated soybean phosphatidylcholine with $80 \%$ PC, which are excellent sole emulsifiers in oil-in-water emulsions,

(2) actives for improving barrier properties are lamellar creams with hydrogenated phosphatidylcholine, hydrogenated soybean phosphatidylcholine with $80 \%$ PC or $90 \%$ PC,

(3) biochemically active nutrients are soybean phosphatidylcholine with $\geq 90 \%$ $\mathrm{PC}$,

(4) skin transport enhancing modalities are liposomal concentrates, described above and soybean phosphatidylcholine with $\geq 90 \%$ PC.

Besides soybean phospholipids, the use of sunflower phospholipid fractions and the respective unsaturated and saturated phosphatidylcholine is becoming increasingly popular.

In spite of the decade-long use of phospholipids, there are still research issues which would be of future interest. For instance, as pointed out above, the knowledge on skin metabolism (anabolism and catabolism) of endogenous and externally applied phospholipids is still very limited. Also, it would be of interest to compare the skin interaction of emulsions (nano- or macro-emulsions) comprising phospholipids with liposomes in much greater detail.

In nano-cosmetics, phospholipids play a role as an essential component in oil-in-water emulsions and liposomes in the size range typical for nanotechnology. Since they belong to the class of nano-materials which fall apart in the skin, they do not pose a risk for systemic absorption but represent material with an excellent skin interaction, which results in optimal cosmetic effects.

The availability of these natural compounds with controlled quality in various grades and modifications provides the formulator with a valuable toolbox for designing optimal cosmetic formulations and products.

\section{References}

1. U.S. Department of Health and Human Services, F., Center For Food Safety And Applied Nutrition. Guidance for Industry: Safety of Nanomaterials in Cosmetic Products; June 2014.

2. Dragicevic-Curic N, Scheglmann D, Albrecht V, Fahr A. Temoporfin-loaded invasomes: development, characterization and in vitro skin penetration studies. J Control Release. 2008;127:59-69.

3. Cevc G, Blume G, Schätzlein A. Transfersomes-mediated transepidermal delivery improves the regio-specificity and biological activity of corticosteroids in vivo. J Controlled Release. 1997;45:211-26.

4. Ashtikar M, Langeluddecke L, Fahr A, Deckert V. Tip-enhanced Raman scattering for tracking of invasomes in the stratum corneum. Biochim Biophys Acta. 2017;1861:2630-9.

5. Lasic DD. Novel applications of liposomes. Trends Biotechnol. 1998;16:307-21.

6. Kraft JC, Freeling JP, Wang Z, Ho RJ. Emerging research and clinical development trends of liposome and lipid nanoparticle drug delivery systems. J Pharm Sci. 2014;103:29-52. 
7. Blaber, M. BCH 4053 Biochemistry I [Online]. Available: http://www.mikeblaber.org/ oldwine/BCH4053/Lecture14/Lecture14.htm (2001). Accessed 20 Feb 2018.

8. Yee JY, Davis ROE. Accelerated method for determining moisture absorption. Ind Eng Chem Anal Ed. 1944;16:487-90.

9. Ghyczy M, Vacata V. Phosphatidylcholine and skin hydration. In: Leyden JJ, Rawlings AV, editors. Skin moisturization, vol. 15. NY: Marcel Dekker Inc., Basel Chapter; 2002. 303-321.

10. van Hoogevest $\mathrm{P}$, Wendel A. The use of natural and synthetic phospholipids as pharmaceutical excipients. Eur J Lipid Sci Technol. 2014;116:1088-107.

11. USP_Monograph. Lecithin Monograph USP40-NF35; 2018.

12. Lekim D, Betzing H. Der Einbau von EPL-Substanz in Organe von gesunden und durch Galaktosamin geschädigten Ratten. Arzneim. Forsch. (Drug Res.). 1974;24:1217-21.

13. Elias PM, Friend DS. The permeability barrier in mammalian epidermis. The J Cell Biol. 1975;65:180-91.

14. Holbrook KA, Odland GF. Regional differences in the thickness (cell layers) of the human stratum corneum: an ultrastructural analysis. J Invest Dermatol. 1974;62:415-22.

15. Honeywell-Nguyen PL, de Graaff AM, Groenink HWW, Bouwstra JA. The in vivo and in vitro interactions of elastic and rigid vesicles with human skin. Biochim Biophys Acta. 2002;1573:130-40.

16. Itoh Y, Shimazu A, Sadzuka Y, Sonobe T, Itai S. Novel method for stratum corneum pore size determination using positron annihilation lifetime spectroscopy. Int $\mathrm{J}$ Pharm. 2008;358:91-5.

17. Ruddy S, Hadzija B. Iontophoretic permeability of polyethylene glycols through hairless rat skin: application of hydrodynamic theory for hindered transport through liquid-filled pores. Drug Des Discov. 1992;8:207-24.

18. Aguilella V, Kontturi K, Murtomäki L, Ramírez P. Estimation of the pore size and charge density in human cadaver skin. J Controlled Release. 1994;32:249-57.

19. Elias PM, Gruber R, Crumrine D, Menon G, Williams ML, Wakefield JS, Holleran WM, Uchida Y. Formation and functions of the corneocyte lipid envelope (CLE). Biochimica et Biophysica Acta (BBA)-Mol Cell Biol Lipids 2014;1841:314-318.

20. Bouwstra J, Honeywell-Nguyen P. Skin structure and mode of action of vesicles. Adv Drug Deliv Rev. 2002;54:S41-55.

21. Ohman $\mathrm{H}$, Vahlquist $\mathrm{A}$. In vivo studies concerning a $\mathrm{pH}$ gradient in human stratum corneum and upper epidermis. Acta Dermatovenereologica-Stockholm, 1994;74:375-375.

22. Korting H, Lukacs A, Vogt N, Urban J, Ehret W Ruckdeschel G Influence of the pH-value on the growth of Staphylococcus epidermidis, Staphylococcus aureus and Propionibacterium acnes in continuous culture. Zentralblatt fur Hygiene und Umweltmedizin = Int $\mathrm{J}$ Hyg Environ Med. 1992; 193:78-90.

23. Puhvel S, Reisner R, Sakamoto M. Analysis of lipid composition of isolated human sebaceous gland homogenates after incubation with cutaneous bacteria. Thin-layer chromatography. J Invest Dermatol. 1975;64:406-11.

24. Feingold KR, Elias PM. Role of lipids in the formation and maintenance of the cutaneous permeability barrier. Biochimica et Biophysica Acta (BBA)-Mol Cell Biol Lipids 2014;1841:280-294.

25. Feingold KR. The outer frontier: the importance of lipid metabolism in the skin. J Lipid Res. 2009;50:S417-22.

26. Mazereeuw-Hautier J, Redoules D, Tarroux R, Charveron M, Salles J, Simon M, Cerutti I, Assalit M, Gall Y, Bonafe J. Identification of pancreatic type I secreted phospholipase A2 in human epidermis and its determination by tape stripping. Br J Dermatol. 2000;142:424-31.

27. Mao-Qiang M, Jain M, Feingold KR, Elias PM. Secretory phospholipase A2 activity is required for permeability barrier homeostasis. J Invest Dermatol. 1996;106:57-63.

28. Cox P, Squier CA. Variations in lipids in different layers of porcine epidermis. J Invest Dermatol. 1986;87:741-4. 
29. Lampe MA, Williams ML, Elias PM. Human epidermal lipids: characterization and modulations during differentiation. J Lipid Res. 1983;24:131-40.

30. Wertz PW, van den Bergh B. The physical, chemical and functional properties of lipids in the skin and other biological barriers. Chem Phys Lipids. 1998;91:85-96.

31. Lampe MA, Burlingame A, Whitney J, Williams ML, Brown BE, Roitman E, Elias PM. Human stratum corneum lipids: characterization and regional variations. J Lipid Res. $1983 ; 24: 120-30$.

32. Bonte F, Saunois A, Pinguet P, Meybeck A. Existence of a lipid gradient in the upper stratum corneum and its possible biological significance. Arch Dermatol Res. 1997;289:78-82.

33. Mauro T, Grayson S, Gao WN, Man M-Q, Kriehuber E, Behne M, Feingold KR, Elias PM. Barrier recovery is impeded at neutral $\mathrm{pH}$, independent of ionic effects: implications for extracellular lipid processing. Arch Dermatol Res. 1998;290:215-22.

34. Fiume Z. Final report on the safety assessment of lecithin and hydrogenated lecithin. Int $\mathbf{J}$ Toxicol. 2001;20(Suppl 1):21-45.

35. ORGAniZATION, U. C. I. R. C. Final Report Release Date: April 7, 2015. Safety Assessment of Lecithin and Other Phosphoglycerides as Used in Cosmetics, CIR Status.

36. Traul K, Driedger A, Ingle D, Nakhasi D. Review of the toxicologic properties of medium-chain triglycerides. Food Chem Toxicol. 2000;38:79-98.

37. Ghyczy M, Vacata V. Concepts for topical formulations adjusted to the structure of the skin. Chim Oggi. 1999;17:12-20.

38. Ghyczy M. Die Hautstruktur und adäquate Kosmetika. Beeinflussung der Permeabilitätsbarriere der Haut mittels Struktur der Kosmetika. Kosmetische Medizin. 1999;20:192-5.

39. Rebmann H. The composition of lecithin and its potential uses in cosmetics. Soap Parf Cosmet. 1977;50:361-70.

40. The Solae Company. Introduction to the use of lecithin, Technical Bulletin; 2003.

41. Knoth A, Scherze I, Fechner A. Emulgatoren zur Bildung von multiplen Emulsionen. Lecithin. In: Muschiolik G, Bunjes H, editors. Multiple Emulsionen: Herstellung und Eigenschaften. Hamburg: Behr's Verlag; 2007.

42. Heidecke CD, Van Hoogevest P, Seckler, D. Use of phospholipids as sole emulsifiers in water-in-oil emulsions. Poster. In: Fifth International Symposium on Phospholipids in Research; 2017; Heidelberg, Germany.

43. Schreier H, Bouwstra J. Liposomes and niosomes as topical drug carriers-dermal and transdermal drug delivery. J Controlled Release. 1994;30:1-15.

44. New RRC, editor. Liposomes: a practical approach. Oxford: IRL Press, Oxford University Press; 1990.

45. Fujita S, Suzuki K. Soyabean lysophospholipid as a surfactant: aqueous solution and wetting properties. Nippon Nogeikagaku Kaishi. 1990;64:1355-60.

46. Johansson D, Bergenståhl B. Lecithins in oil-continuous emulsions. Fat crystal wetting and interfacial tension. J Am Oil Chem Soc. 1995;72:205-11.

47. Artmann C, Röding J, Ghyczy M, Pratzel HG. Influence of various liposome preparations on skin humidity. Parfum Kosm. 1990;90:326.

48. Ghyczy M, Gareiss J, Kovats T. Liposomes from vegetable phosphatidylcholine: their production and effects on the skin. Cosmetics and toiletries. 1994;109:75-80.

49. Lautenschläger H. Starke Wirkung-Phospholipide in Kosmetika. Kosmetik Int. 2003;2:38-40.

50. Ghyczy M, Albrecht M, Vacata V. Phospholipids, Metabolites, and Skin Hydration. In: Lodén M, Maibach HI, editors. Dry skin and moisturizers: chemistry and function. Boca Raton: CRC Press Taylor \& Francis Group.

51. Fabrizi G, Randazzo SD, Cardillo A, Tiberi L, Morganti P. Safety and efficacy of lamellar phosphatidylcholine emulsion to treat mild-to-moderate inflammatory acne. SOFW-J. 1999;125:12-4.

52. Ghyczy M, Nissen H, Biltz H. The treatment of acne vulgaris by phosphatidylcholine from soybeans, with a high content of linoleic acid. J Appl Cosmetol. 1996;14:137-46. 
53. Kutz G. Galenische Charakterisierung ausgewählter Hautpflegeprodukte. PZ 142, 1997; 142:11-15.

54. Morck H. Liposomen bei Neurodermitis und Psoriasis. PZ. 1993;128:50-1.

55. Takahashi T, Kamimura A, Hamazono-Matsuoka T, Honda S. Phosphatidic acid has a potential to promote hair growth in vitro and in vivo, and activates mitogen-activated protein kinase/extracellular signal-regulated kinase kinase in hair epithelial cells. J Invest Dermatol. 2003;121:448-56.

56. JP2008143835. Vascular endothelial cell growth inhibitor and/or angiogenesis inhibitor. JP 2008143835; 2006.

57. Chung S-Y, Nam S-J, Choi W-K, Seo M-Y, Kim J-W, Lee S-H, Park C-S. Phosphatidylserine enhances skin barrier function through keratinocyte differentiation. J Soc Cosmet Sci Korea. 2006;32:17-22.

58. Verma DD, Verma S, Blume G, Fahr A. Liposomes increase skin penetration of entrapped and non-entrapped hydrophilic substances into human skin: a skin penetration and confocal laser scanning microscopy study. Eur J Pharm Biopharm. 2003;55:271-7.

59. Verma DD, Verma S, Blume G, Fahr A. Particle size of liposomes influences dermal delivery of substances into skin. Int J Pharm. 2003;258:141-51.

60. Chen M, Liu X, Fahr A. Skin penetration and deposition of Carboxyfluorescein and Temoporfin from different lipid vesicular systems: in vitro study with finite and infinite dosage application. Int J Pharm. 2011.

61. Kim C, Shim J, Han S, Chang I. The skin-permeation-enhancing effect of phosphatidylcholine: caffeine as a model active ingredient. J Cosmet Sci. 2002;53:363-74.

62. Röding J. Properties and characterization of pre-liposome systems. In: Braun-Falco O, Korting HC, Maibach HI, editors. Liposome dermatics. Heidelberg, Berlin: Springer; 1992.

63. Röding J, Artmann C. The fate of liposomes in animal skin. In: Braun-Falco O, Korting HC, Maibach HI, editors. Liposome dermatics. Heidelberg, Berlin: Springer; 1992.

64. Korting HC, Schollmann C. Resistance of liposomal sunscreen formulations against plain water as well as salt water exposure and perspiration. Skin Pharmacol Physiol. 2011;24:3643.

65. Gottbrath S, Müller-Goymann C. Penetration and visualization of titanium dioxide microparticles in human stratum corneum - effect of different formulations on the penetration of titanium dioxide. SOFW-J. 2003;129:11-7.

66. Shigeta Y, Imanaka H, Ando H, Ryu A, Oku N, Baba N, Makino T. Skin whitening effect of linoleic acid is enhanced by liposomal formulations. Biol Pharm Bull. 2004;27:591-4.

67. Coderch L, de Pera M, Perez-Cullell N, Estelrich J, de la Maza A, Parra J. The effect of liposomes on skin barrier structure. Skin Pharm Physiol. 1999;12:235-46.

68. Van Kuijk-Meuwissen ME, Mougin L, Junginger HE, Bouwstra JA. Application of vesicles to rat skin in vivo: a confocal laser scanning microscopy study. J Controlled Release. 1998;56:189-96.

69. Fahr A, Schäfer U, Verma D, Blume G. Skin penetration enhancement of substances by a novel type of liposomes. SÖFW-J. 2000;126:48-53.

70. Perez-Cullell N, Coderch L, de la Maza A, Parra JL, Estelrich J. Influence of the fluidity of liposome compositions on percutaneous absorption. Drug Deliv. 2000;7:7-13.

71. Yokomizo Y, Sagitani H. Effects of phospholipids on the in vitro percutaneous penetration of prednisolone and analysis of mechanism by using attenuated total reflectance-Fourier transform infrared spectroscopy. J Pharm Sci. 1996;85:1220-6.

72. Komatsu H, Higaki K, Okamoto H, Miyagawa K, Hashida M, Sezaki H. Preservative activity and in vivo percutaneous penetration of butylparaben entrapped in liposomes. Chem Pharm Bull. 1986;34:3415-22.

73. Ibrahim SA, Li SK. Efficiency of fatty acids as chemical penetration enhancers: mechanisms and structure enhancement relationship. Pharm Res. 2010;27:115.

74. du Plessis J, Egbaria K, Ramachandran C, Weiner N. Topical delivery of liposomally encapsulated gamma-interferon. Antiviral Res. 1992;18:259-65. 
75. Lieb LM, Ramachandran C, Egbaria K, Weiner N. Topical delivery enhancement with multilamellar liposomes into pilosebaceous units: I. In vitro evaluation using fluorescent techniques with the hamster ear model. J Invest Dermatol. 1992;99:108-13.

76. Niemiec SM, Ramachandran C, Weiner N. Influence of nonionic liposomal composition on topical delivery of peptide drugs into pilosebaceous units: an in vivo study using the hamster ear model. Pharm Res. 1995;12:1184-8.

77. Li L, Hoffman RM. Topical liposome delivery of molecules to hair follicles in mice. J Dermatol Sci. 1997;14:101-8.

78. Trauer, S., et al., Influence of massage and occlusion on the ex vivo skin penetration of rigid liposomes and invasomes. Eur. J. Pharm. Biopharm. 2014;86(2):301-6.

79. Orsinger K. Lecithin in der Haarkosmetik. SOFW J. 1983;109:495-9.

80. Wajda R, Zirkel J, Sauter K. NanoSolve: an advanced carrier system for cosmetic application. Cosmetic Sci Technol. 2009;1:11-4.

81. Hoepfner E-M, Fiedler HP. Fiedler Encyclopedia of excipients : for pharmaceuticals, cosmetics and related areas. Aulendorf, ECV Editio Cantor Verlag; 2007.

82. Morsy E. Applied liposomology natipide II. F2CO, 1992; 149-151.

83. Röding J. Natipide ${ }^{\circledR}$ II: new easy liposome system. SOFW J. 1990;116:509-15.

84. Lautenschläger H. Liposomes. In: Barel AO, Paye M, Maibach HI, editors. Handbook of cosmetics, science and technology. Boca Raton: CRC Press Taylor \& Francis Group; 2006.

85. van Hoogevest P, Prusseit B, Wajda R. Phospholipids: natural functional lngredients and actives for cosmetic products. SOFW-J. 2013;139:9-15.

Open Access This chapter is licensed under the terms of the Creative Commons Attribution 4.0 International License (http://creativecommons.org/licenses/by/4.0/), which permits use, sharing, adaptation, distribution and reproduction in any medium or format, as long as you give appropriate credit to the original author(s) and the source, provide a link to the Creative Commons license and indicate if changes were made.

The images or other third party material in this chapter are included in the chapter's Creative Commons license, unless indicated otherwise in a credit line to the material. If material is not included in the chapter's Creative Commons license and your intended use is not permitted by statutory regulation or exceeds the permitted use, you will need to obtain permission directly from the copyright holder.

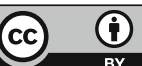

